\title{
Ozonation of sitagliptin: removal kinetics and elucidation of oxidative transformation products
}

Nina Hermes ${ }^{\alpha}$, Kevin S. Jewell ${ }^{\alpha}$, Per Falås ${ }^{\beta}$, Holger V. Lutze ${ }^{\gamma}$, Arne Wick ${ }^{\alpha}$, Thomas A. Ternes*a

${ }^{\alpha}$ Federal Institute of Hydrology, Mainzer Tor 1, 56068 Koblenz, Germany

${ }^{\beta}$ Department of Chemical Engineering, Lund University, PO Box 124, 22100 Lund, Sweden

${ }^{\gamma}$ University of Duisburg-Essen, Faculty of Chemistry, Instrumental Analytical Chemistry, Universitätsstraße 5, 45141 Essen

*Corresponding author: phone: +49 2611306 5560, fax: +49 2611306 536, email: ternes@bafg.de

This supporting information contains (i) information about consumption numbers of STG in Germany, (ii) details of the LC- and IC-ESI-QTOF methods, (iii) results of the attenuation of STG at different $\mathrm{pH}$ values during kinetic studies, (iv) detailed information on detected TPs and description of obtained MS2 spectra, (v) information about TFA formation during batch experiments at different $\mathrm{pH}$ values, (vi) results of attenuation of STG in comparison to other substances and TFA formation in ozonation of WWTP effluent and (vii) detailed description and results from the attenuation of the main ozonation TP during MBBR treatment in batch experiments and in a pilot plant. 


\section{Supporting Information}

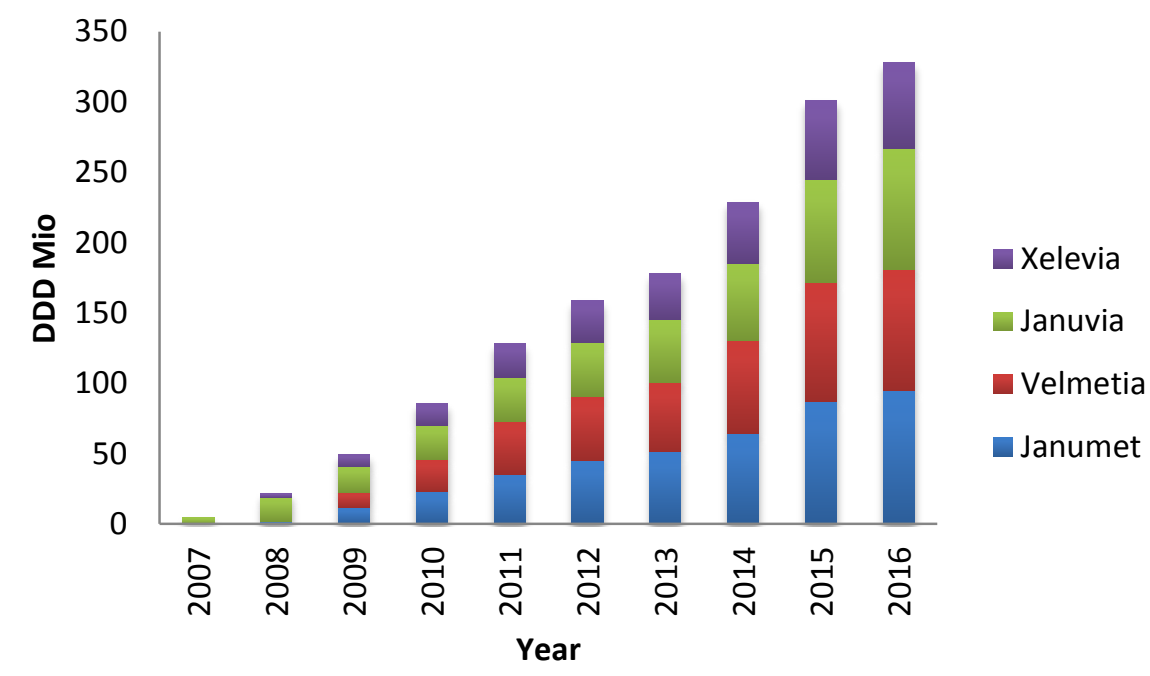

Figure S1. Consumption numbers of four STG preparations in Germany for the years 2007 - 2016.

Januvia and Xelevia are single agent preparations of STG while Velmetia and Janumet are combination preparations with metformin. Consumption numbers increased steadily over the shown time period. 
Supporting Information

Table S1. Wastewater characteristic before and after ozonation in the ozonation pilot plant at the WWTP Lundakra (average \pm standard deviation, $n=3$ )

\begin{tabular}{|c|c|c|c|c|c|c|c|c|}
\hline & \multicolumn{2}{|c|}{$0.3 \mathrm{mg} \mathrm{O}_{3} / \mathrm{mg} \mathrm{DOC}$} & \multicolumn{2}{|c|}{$0.5 \mathrm{mg} \mathrm{O}_{3} / \mathrm{mg} \mathrm{DOC}$} & \multicolumn{2}{|c|}{$0.7 \mathrm{mg} \mathrm{O}_{3} / \mathrm{mg} \mathrm{DOC}$} & \multicolumn{2}{|c|}{$0.9 \mathrm{mg} \mathrm{O}_{3} / \mathrm{mg} \mathrm{DOC}$} \\
\hline Matrix & Influent & Effluent & Influent & Effluent & Influent & Effluent & Influent & Effluent \\
\hline $\begin{array}{l}\text { Temperature } \\
\left({ }^{\circ} \mathrm{C}\right)\end{array}$ & $11.0+0.6$ & $10.9+0.5$ & $11.1+0.2$ & $11.1+0.1$ & $11.9+0.7$ & $11.9+0.7$ & $13.4+0.4$ & $13.6+0.5$ \\
\hline $\mathrm{pH}$ & $7.4+0.0$ & $7.3+0.1$ & $7.3+0.1$ & $7.3+0.1$ & $7.3+0.0$ & $7.5+0.3$ & $7.3+0.0$ & $7.2+0.0$ \\
\hline $\mathrm{DOC}(\mathrm{mg} / \mathrm{L})$ & $10.6+0.1$ & $10.5+0.9$ & $10.4+0.6$ & $10.8+0.9$ & $10.4+0.2$ & $10.6+0.7$ & $10.6+0.4$ & $11.0+1.2$ \\
\hline $\begin{array}{l}\mathrm{COD}_{\text {dissolved }} \\
\text { (mg/L) }\end{array}$ & $25.5+0.2$ & $25.5+2.2$ & $26.3+1.6$ & $26.4+2.5$ & $25.0+1.7$ & $24.5+1.2$ & $26.6+1.1$ & $25.4+2.3$ \\
\hline $\mathrm{NH}_{4}-\mathrm{N}(\mathrm{mg} / \mathrm{L})$ & $4.3+0.7$ & $4.4+0.7$ & $4.6+0.3$ & $4.7+0.3$ & $5.1+0.3$ & $5.1+0.2$ & $3.9+0.1$ & $3.9+0.1$ \\
\hline $\mathrm{NO}_{3}-\mathrm{N}(\mathrm{mg} / \mathrm{L})$ & $1.0+0.3$ & $1.6+0.2$ & $1.2+0.1$ & $1.5+0.2$ & $0.8+0.2$ & $1.2+0.3$ & $0.8+0.3$ & $1.1+0.2$ \\
\hline $\mathrm{NO}_{2}-\mathrm{N}(\mathrm{mg} / \mathrm{L})$ & $0.4+0.2$ & $0.1+0.1$ & $0.20+0.02$ & $<0.05$ & $0.24+0.06$ & $<0.05$ & $0.3+0.1$ & $<0.05$ \\
\hline $\begin{array}{l}\text { Suspended } \\
\text { solids (mg/L) }\end{array}$ & $24.1+18.2$ & $16.0+8.9$ & $11.7+4.5$ & $12.0+1.7$ & $6.7+3.1$ & $4.7+0.6$ & $5.0+1.7$ & $3.7+0.6$ \\
\hline
\end{tabular}




\section{Supporting Information}

Table S2. Details on the LC-ESI-QTOF analysis method

\begin{tabular}{|l} 
LC Agilent Technologies 1260 Infinity Series \\
Synergie Hydro-RP $(3 \times 250 \mathrm{~mm} ; 4 \mu \mathrm{m})$ \\
Temp.: $40^{\circ} \mathrm{C}$ \\
Flow: $450 \mu \mathrm{L} / \mathrm{min}$, injection: $50 \mu \mathrm{L}$ \\
A: Water $+0.1 \% \mathrm{HCOOH}$, \\
B: $\mathrm{CH}_{3} \mathrm{CN}+0.1 \% \mathrm{HCOOH}$ \\
Run time: 30 min \\
Gradient: \\
\\
\end{tabular}

For evaluation of removal kinetics, quantification of STG was performed. To account for any random uncertainties, STG-d4 was added to the samples. Calibration curves were drawn for the uncorrected peak area as well as for area ratio of STG-STG-d4.

Good linearity was achieved in the concentration range of $0-1 \mathrm{mg} / \mathrm{L}$.

To obtain further information about concentrations of TP 406, also for comparison of ionizability of TP 406 to STG, calibration curves for TP 406 were prepared with the area of TP 406 as well as the area ration TP 406:STG-d4.

Good linearity was achieved in the concentration range of $0-0.4 \mathrm{mg} / \mathrm{L}$. 


\section{Supporting Information}

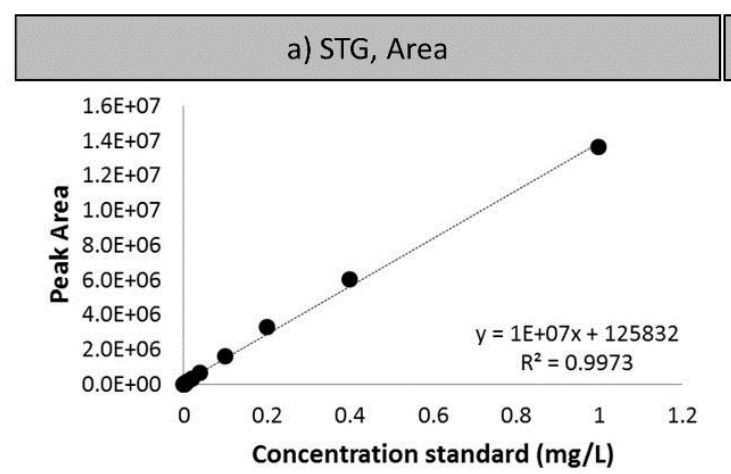

b) STG, Area ratio STG:STG-d4
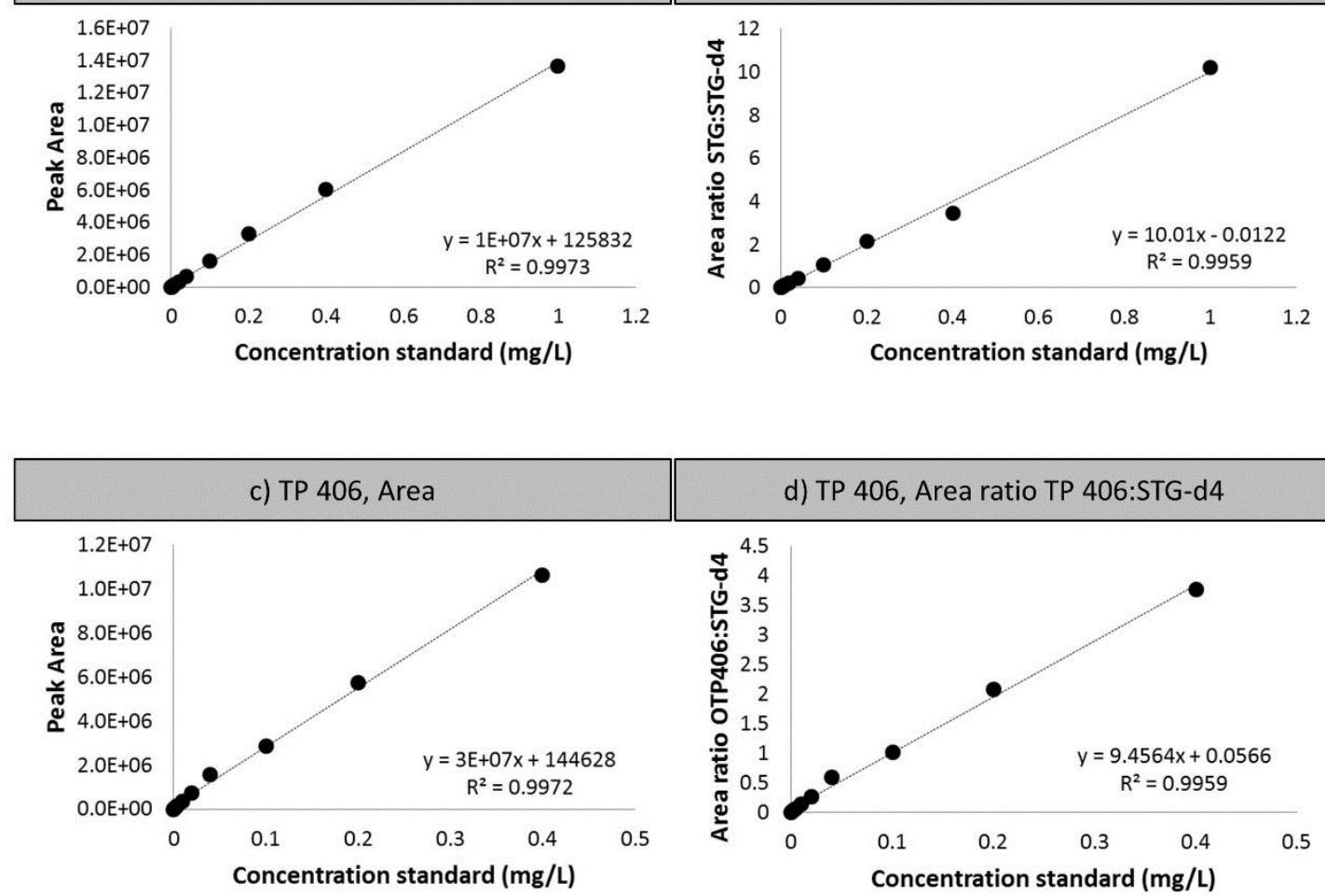

d) TP 406, Area ratio TP 406:STG-d4

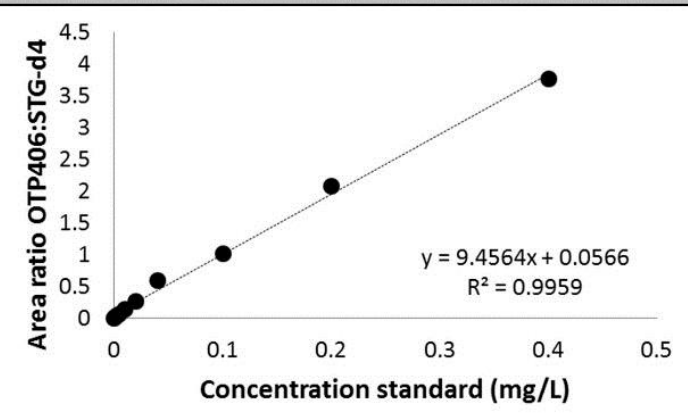

Figure S2. External calibration of STG and TP 406 at the LC-ESI-QTOF using STG-d4 as internal standard 


\section{Supporting Information}

Table S3. Details on the IC-ESI-QTOF analysis method

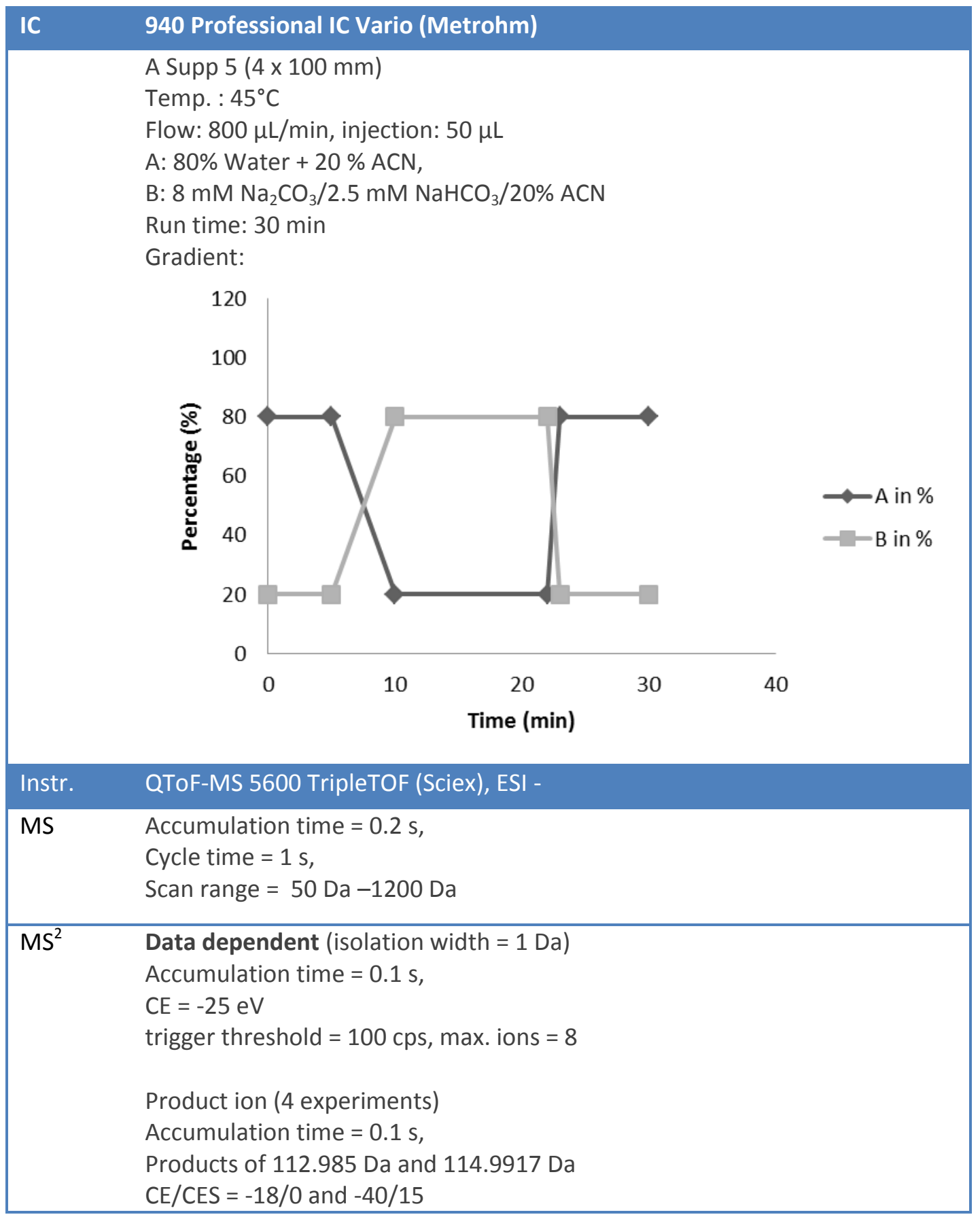

For quantification purposes, calibration curves were prepared for TFA by plotting the area against the concentration of the standards as well as plotting the area ration of TFA:TFA-13C2.

Good linearity was achieved for the concentration range of $0-60 \mu \mathrm{g} / \mathrm{L}$. 


\section{Supporting Information}

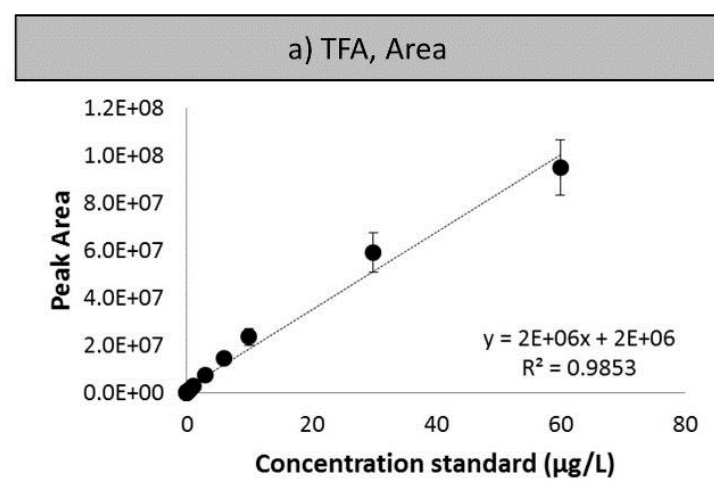

b) TFA, Area ratio TFA:13C2 TFA

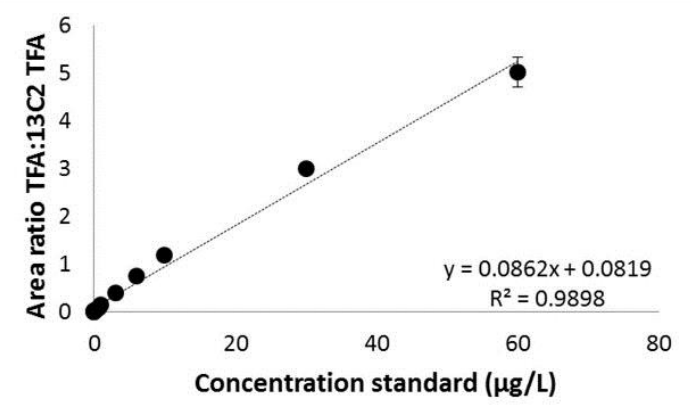

Figure S3. External calibration of TFA at the IC-ESI-QTOF using TFA-13C2 as internal standard 
a) Attenuation STG with t-BuOH

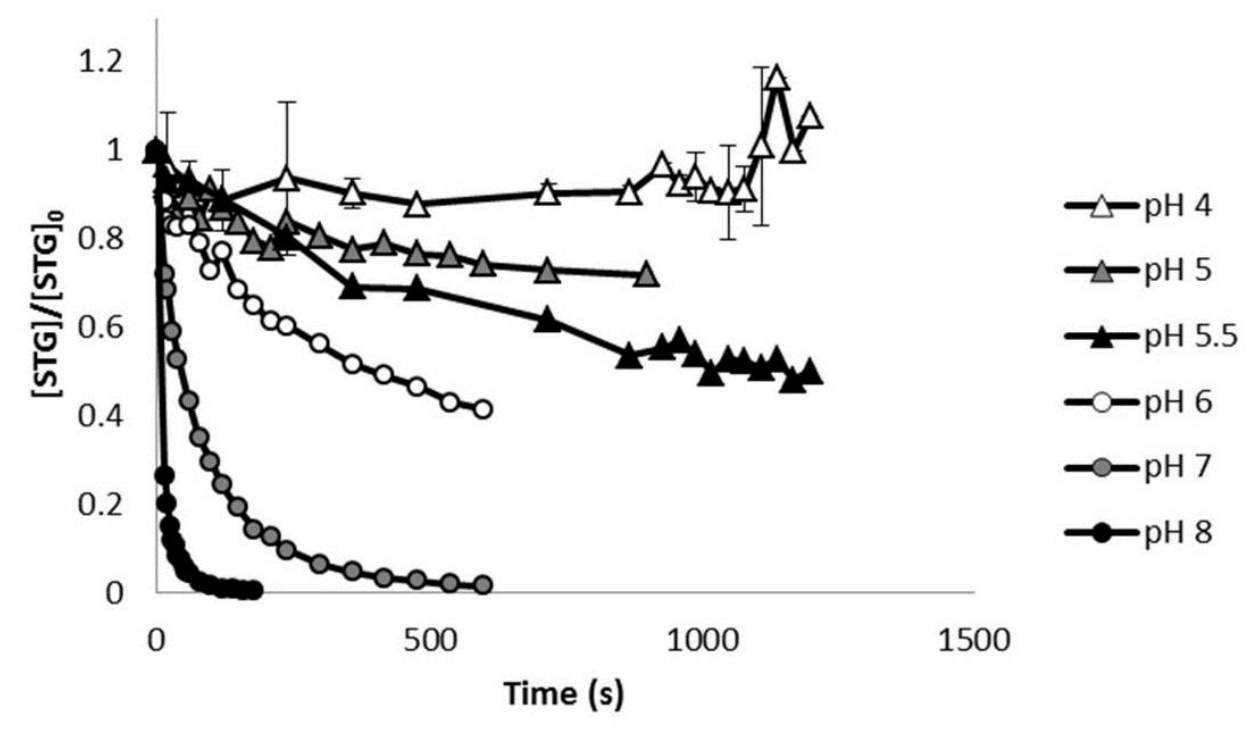

b) Attenuation STG without t-BuOH

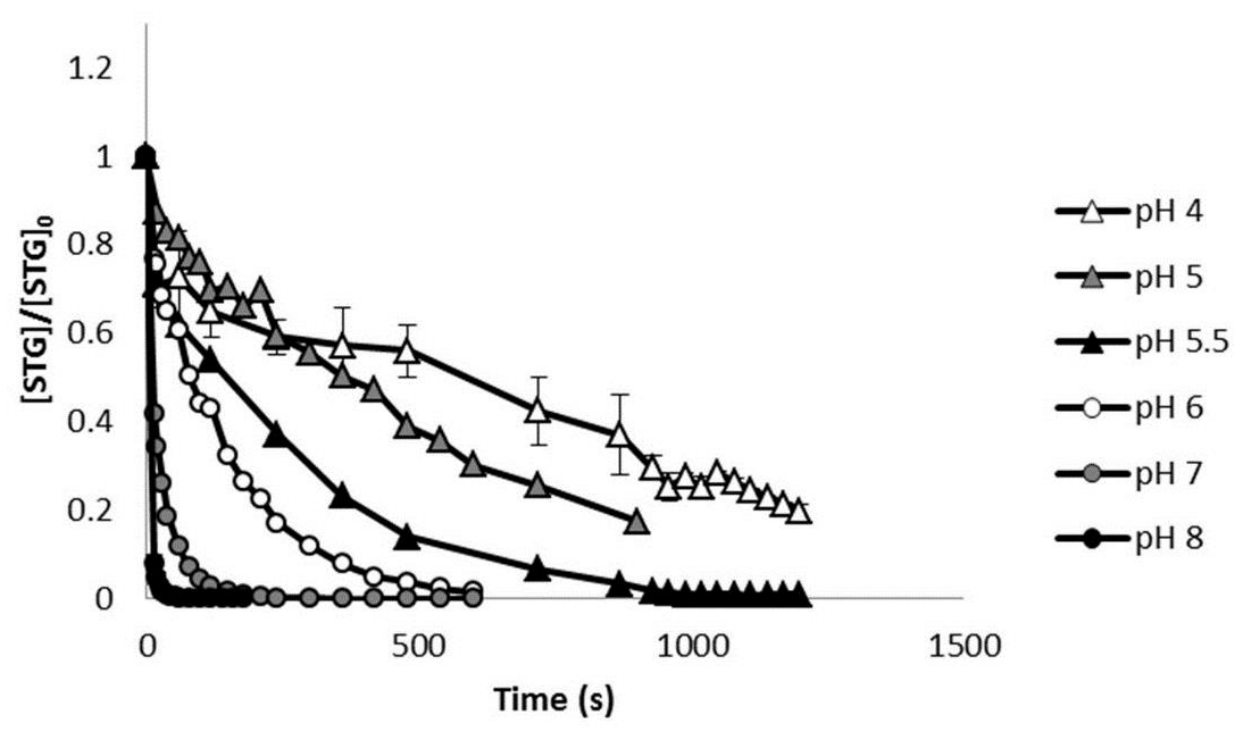

Figure S4. Attenuation of STG in in $50 \mathrm{mM}$ phosphate buffer at different $\mathrm{pH}$ values in presence and absence of $\mathrm{t}-\mathrm{BuOH}$ as radical scavenger 


\section{Supporting Information}

Table S4. Overview of observed potential TPs in time series experiments ( $50 \mathrm{mM}$ phosphate buffer). 32 potential TPs could be detected in the time-series experiments. The table contains information about the retention times (RT), exact masses in positive and negative ESI, RT in IC-ESI-QTOF, formation at different pH values and maximum intensities at $\mathrm{pH} 8$

\begin{tabular}{|c|c|c|c|c|c|c|c|c|c|c|c|c|}
\hline \multirow[b]{3}{*}{ TP } & \multirow{2}{*}{\multicolumn{3}{|c|}{ LC }} & \multirow{3}{*}{$\frac{\text { IC }}{R T}$} & \multicolumn{8}{|c|}{ Formation in time series } \\
\hline & & & & & & h t-Bu & & wit & out $t-B$ & $\mathrm{OH}$ & highest Inten & ty pH 8 pos/neg \\
\hline & RT & {$[\mathrm{M}+\mathrm{H}]^{+}$} & {$[\mathrm{M}-\mathrm{H}]^{-}$} & & pH 4 & pH 6 & pH 8 & pH 4 & pH 6 & pH 8 & with t-BuOH & without t-BuOH \\
\hline 407, STG & 10.2 & 408.126 & 452.1153 & - & & & & & & & $22500 / 10000$ & $17800 / 8500$ \\
\hline
\end{tabular}

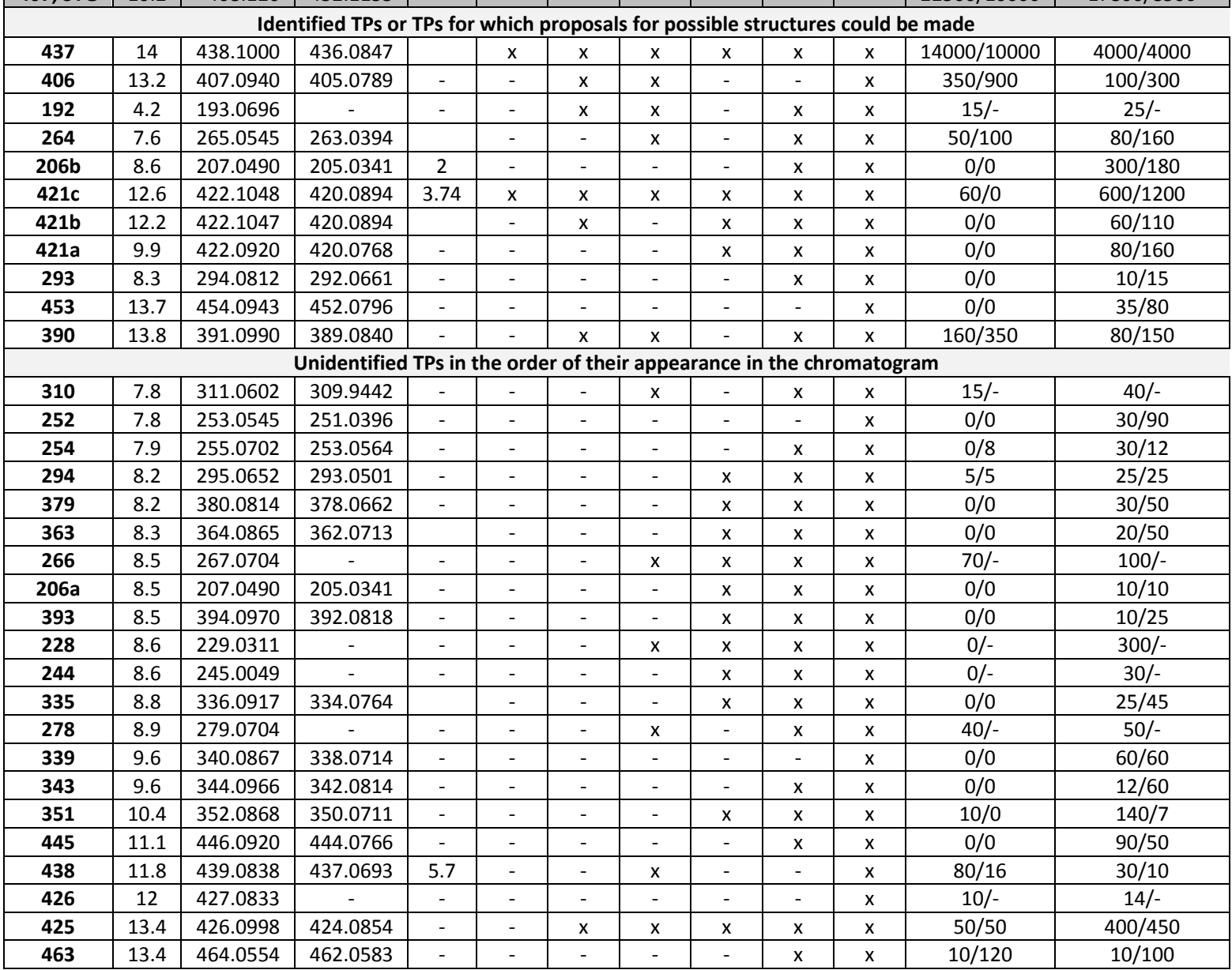



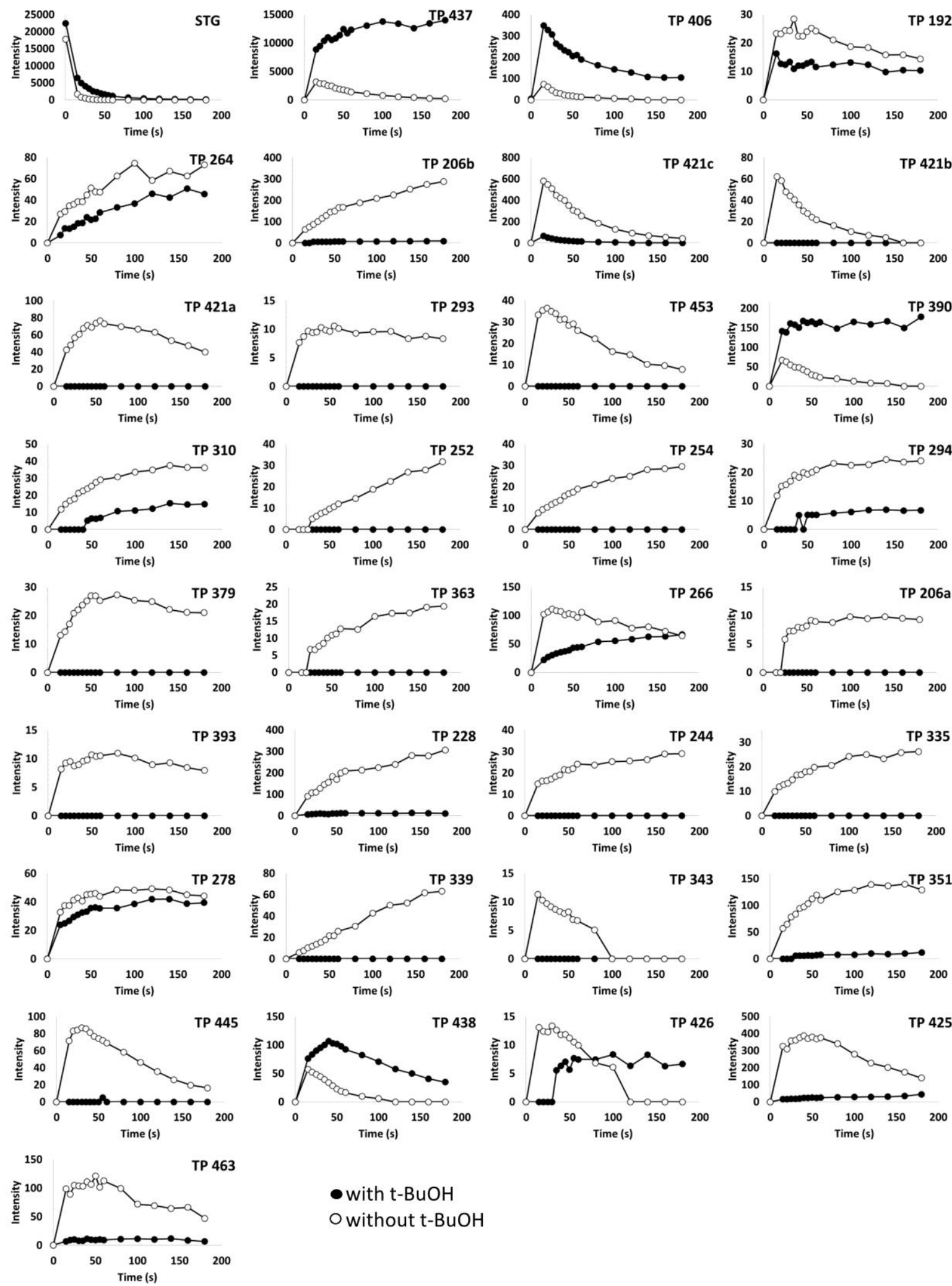

- with t-BuOH

O without t-BuOH

Figure S5. Occurrence of TPs in the time series of $\mathrm{pH} 8,50 \mathrm{mM}$ phosphate buffer, with and without t-

$\mathrm{BuOH}$ 
Table S5. Overview of observed potential TPs in WWTP effluent (batch experiments (WWTP Koblenz): DOC = $12 \mathrm{mg} / \mathrm{L}, \mathrm{pH}=8$, spike STG: $1 \mathrm{mg} / \mathrm{L}$; pilot plant (WWTP Lundakra): DOC = $10 \mathrm{mg} / \mathrm{L}, \mathrm{pH}=7$ ). The table contains information about the retention times (RT), exact masses in positive and negative ESI and formation of TPs in WWTP effluent

\begin{tabular}{|c|c|c|c|c|c|c|}
\hline & \multicolumn{3}{|c|}{ LC } & \multicolumn{2}{|c|}{ batch experiments } & \multirow[t]{2}{*}{ pilot plant } \\
\hline TP & RT & {$[\mathrm{M}+\mathrm{H}]^{+}$} & {$[\mathrm{M}-\mathrm{H}]^{-}$} & spike STG & non-spike & \\
\hline 407, STG & 10.2 & 408.126 & 452.1153 & & & \\
\hline \multicolumn{7}{|c|}{ Identified TPs or TPs for which proposals for possible structures could be made } \\
\hline 437 & 14 & 438.1000 & 436.0847 & $\mathrm{x}$ & $\mathrm{x}$ & $\mathrm{x}$ \\
\hline 406 & 13.2 & 407.0940 & 405.0789 & $x$ & Influent & Influent \\
\hline 192 & 4.2 & 193.0696 & - & $x$ & Influent & Influent \\
\hline 264 & 7.6 & 265.0545 & 263.0394 & $x$ & $x$ & - \\
\hline $206 b$ & 8.6 & 207.0490 & 205.0341 & $x$ & $x$ & $x$ \\
\hline 421c & 12.6 & 422.1048 & 420.0894 & $x$ & $x$ & $x$ \\
\hline $421 b$ & 12.2 & 422.1047 & 420.0894 & $x$ & $x$ & - \\
\hline $421 a$ & 9.9 & 422.0920 & 420.0768 & $x$ & - & - \\
\hline 293 & 8.3 & 294.0812 & 292.0661 & $x$ & - & - \\
\hline 453 & 13.7 & 454.0943 & 452.0796 & $x$ & - & - \\
\hline 390 & 13.8 & 391.0990 & 389.0840 & $x$ & - & - \\
\hline \multicolumn{7}{|c|}{ Unidentified TPs in the order of their appearance in the chromatogram } \\
\hline 310 & 7.8 & 311.0602 & 309.9442 & $\mathrm{x}$ & - & - \\
\hline 252 & 7.8 & 253.0545 & 251.0396 & $\mathrm{x}$ & - & - \\
\hline 254 & 7.9 & 255.0702 & 253.0564 & $\mathrm{x}$ & - & - \\
\hline 294 & 8.2 & 295.0652 & 293.0501 & $x$ & - & - \\
\hline 379 & 8.2 & 380.0814 & 378.0662 & $x$ & - & - \\
\hline 363 & 8.3 & 364.0865 & 362.0713 & $x$ & - & - \\
\hline 266 & 8.5 & 267.0704 & - & $x$ & - & - \\
\hline $206 a$ & 8.5 & 207.0490 & 205.0341 & $x$ & - & - \\
\hline 393 & 8.5 & 394.0970 & 392.0818 & $x$ & - & - \\
\hline 228 & 8.6 & 229.0311 & - & $x$ & $x$ & - \\
\hline 244 & 8.6 & 245.0049 & - & $x$ & - & - \\
\hline 335 & 8.8 & 336.0917 & 334.0764 & $x$ & - & - \\
\hline 278 & 8.9 & 279.0704 & - & $x$ & - & - \\
\hline 339 & 9.6 & 340.0867 & 338.0714 & $x$ & - & - \\
\hline 343 & 9.6 & 344.0966 & 342.0814 & $x$ & - & - \\
\hline 351 & 10.4 & 352.0868 & 350.0711 & $x$ & $x$ & - \\
\hline 445 & 11.1 & 446.0920 & 444.0766 & $x$ & - & - \\
\hline 438 & 11.8 & 439.0838 & 437.0693 & $x$ & - & - \\
\hline 426 & 12 & 427.0833 & - & $x$ & - & - \\
\hline 425 & 13.4 & 426.0998 & 424.0854 & $x$ & $x$ & $x$ \\
\hline 463 & 13.4 & 464.0554 & 462.0583 & $x$ & - & - \\
\hline
\end{tabular}



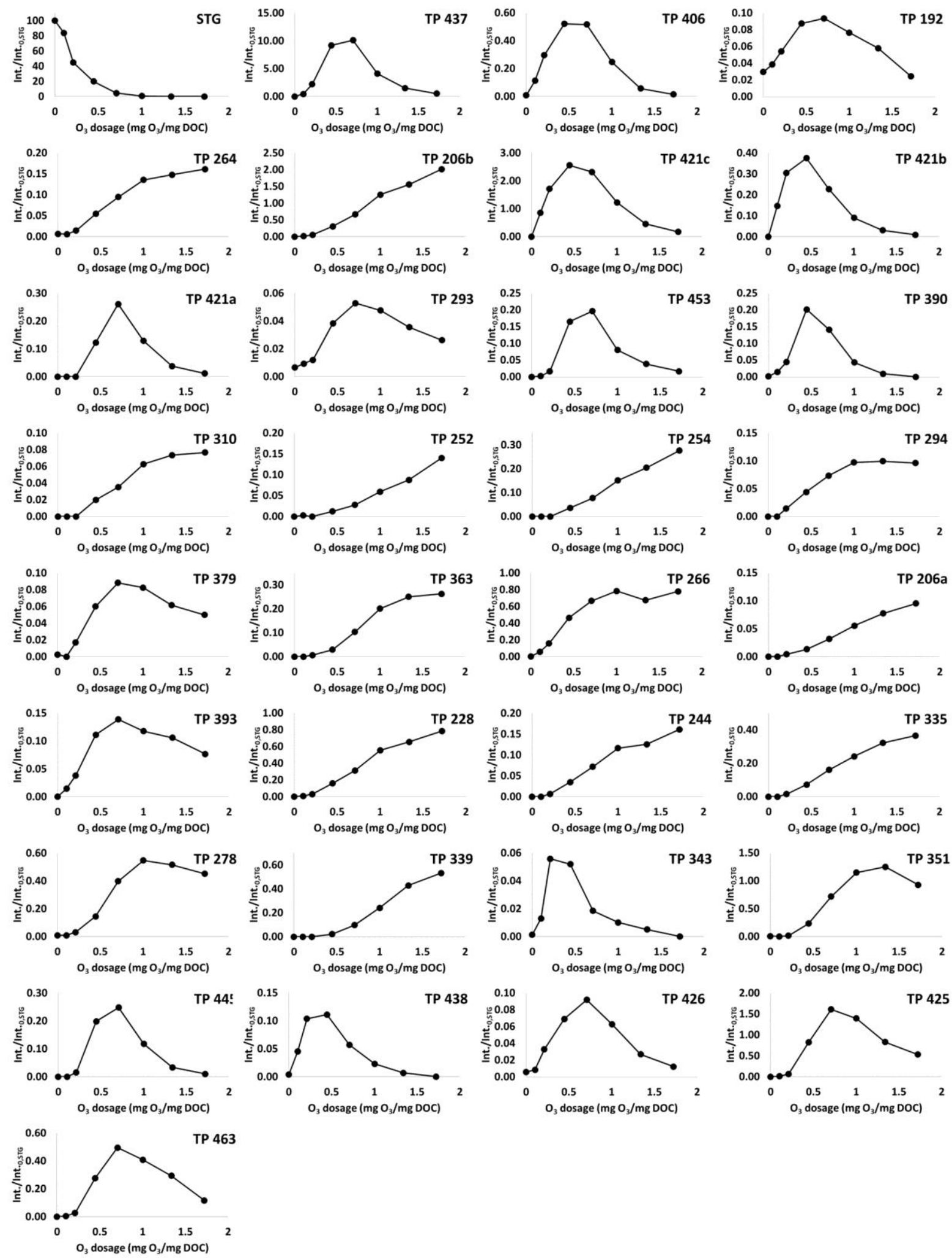

Figure S6. Occurrence of TPs in batch experiments in WWTP effluent with spiked STG (DOC $=12$ $\mathrm{mg} / \mathrm{L}, \mathrm{pH}=8$, spike STG $=1 \mathrm{mg} / \mathrm{L}$ )

Text S1. Structure elucidation for observed TPS 


\section{Supporting Information}

Structure elucidation was based on the obtained $\mathrm{MS}^{2}$ data. In a first step the $\mathrm{MS}^{2}$ spectrum of STG was investigated and structures were assigned to the fragments to identify characteristic fragments. In a seconds step the $\mathrm{MS}^{2}$ spectra of the TPs were searched for the characteristic fragments as well as for specific losses such as $-\mathrm{H}_{2} \mathrm{NO}(-47.00),-\mathrm{NH}_{3}(-17.03),-\mathrm{CO}_{2}(-43.99),-\mathrm{COOH}(-44.99)$ etc. The insilico fragmentation tool MetFrag (https://msbi.ipb-halle.de/MetFragBeta/) was searched for TP structures by calculating the neutral mass from the parent ion of the ionization, using the obtained MS2 data for the fragmentation settings and filtering for structures that obtain only $\mathrm{C}, \mathrm{N}, \mathrm{O}, \mathrm{H}$ and/or F. Molecular formulas were derived from the exact masses via ChemCalc (https://www.chemcalc.org/mf finder), giving an MF range of C 0-16, H 0-100, N 0-5, O 0-10 and F 06 with a mass range of 0.5 .

STG: In positive ESI the small quasi-molecular ion shows the good fragmentability of STG. The loss of -17 with a change from even to uneven $\mathrm{m} / \mathrm{z}$ can be attributed to a loss of $\mathrm{NH} 2$ leading to fragment $\mathrm{m} / \mathrm{z}$ 391.098. Fragments $\mathrm{m} / \mathrm{z} 174.053$ and 171.042 can be assigned to the benzoyl part of STG, while fragment $\mathrm{m} / \mathrm{z} 193.069$ gives the triazole-piperazine unit. In negative ESI STG is detected in the form of an adduct at $\mathrm{m} / \mathrm{z} 452.114$. The fragment $\mathrm{m} / \mathrm{z} 406.11$ corresponds to STG and it also can be detected with very low intensity in the MS1 spectrum. Base peak of STG in negative ionization is $\mathrm{m} / \mathrm{z}$ 191.056 which corresponds to the triazole-piperazine unit. This fragment is will be used as characteristic fragment for the identification of TPs in negative ESI.
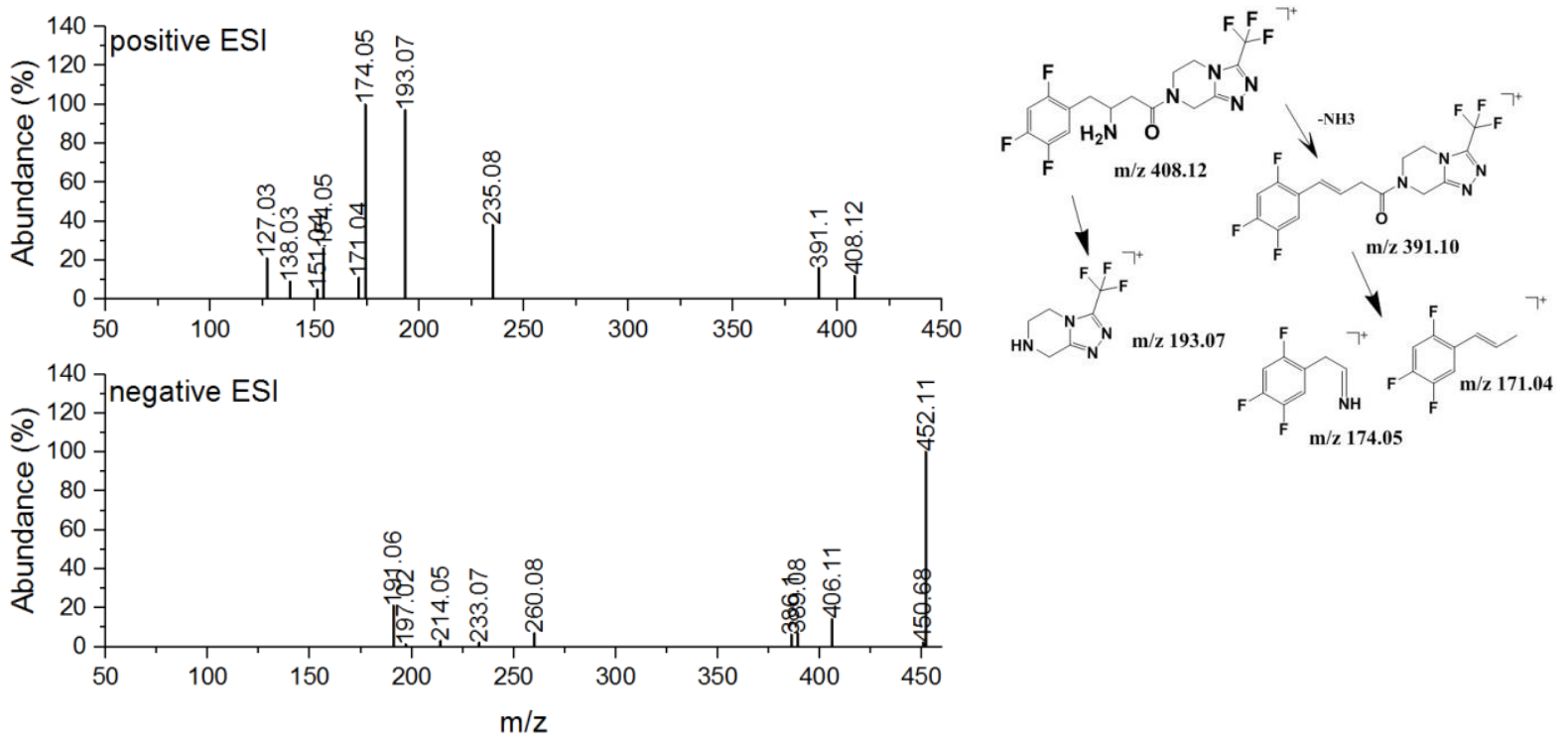

Figure S7. MS2 spectra of STG in positive and negative ESI (left) and characteristic fragments in positive ESI (right)

TP 437: In positive ESI the loss of -47 could be observed from the quasi-molecular ion at $\mathrm{m} / \mathrm{z} 438.09$ to the fragment $\mathrm{m} / \mathrm{z}$ 391.10. This loss could be assigned to HNO2 which is characteristic for aliphatic nitro compounds in electron impact and atmospheric pressure ionization ${ }^{1,2}$. The presence of $\mathrm{m} / \mathrm{z}$ 193.07, $\mathrm{m} / \mathrm{z} 171.04$ and $\mathrm{m} / \mathrm{z} 145.03$ confirms that the basic structure of STG was maintained. Thus, the primary amine of STG was converted into a nitro group. The presence of $\mathrm{m} / \mathrm{z} 191.06$ as base peak in the MS2 of negative ESI confirms the presence of the unchanged triazole-piperazine unit. The same MS2 spectrum for the same exact mass was also detected in IC-ESI-QTOF at a retention time of $4.4 \mathrm{~min}$. Retardation in IC can be explained by a partially negatively charged C-atom at the 


\section{Supporting Information}

nitro group at the $\mathrm{pH}$ of the IC eluent. A search in MetFrag with the obtained MS2 data confirmed the structure, the molecular formula is $\mathrm{C} 16 \mathrm{H} 13 \mathrm{~F} 6 \mathrm{~N} 5 \mathrm{O} 3$.
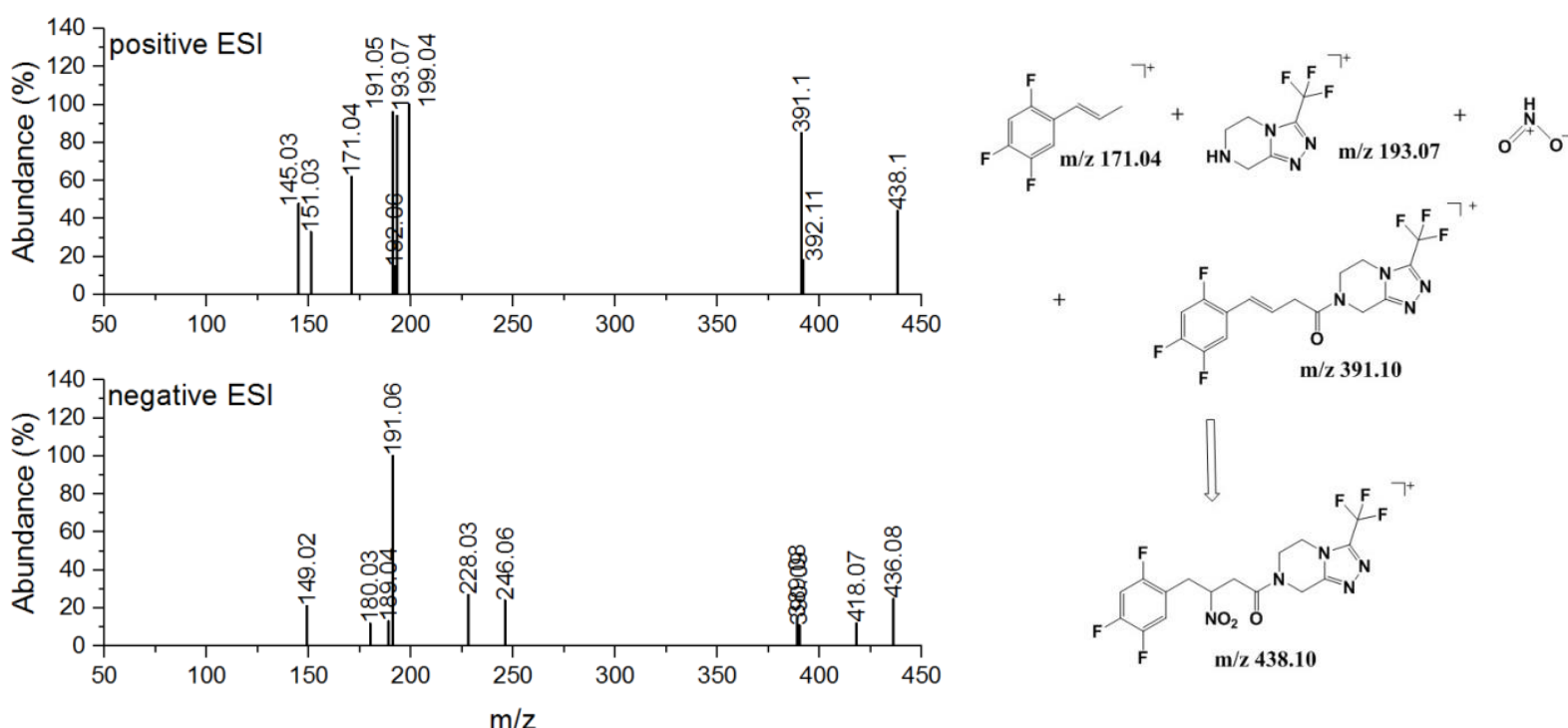

Figure S8. MS2 spectra of TP 437 in positive and negative ESI (left) and structure elucidation in positive ESI (right)

TP 406: For TP 406 characteristic fragments for the benzoyl unit $(\mathrm{m} / \mathrm{z} 145.03)$ and for the triazolepiperazine unit ( $\mathrm{m} / \mathrm{z}$ 193.07) could be detected in positive ESI. Some low intensity, higher mass fragments could be found showing a loss of -18 to the quasi-molecular ion, indicating the presence of oxygen groups. The presence of the unchanged triazole-piperazole unit is confirmed by the fragment $\mathrm{m} / \mathrm{z} 191.06$ which, as for STG and TP 437, is the base peak in the MS2 spectrum of negative ionization. A reference standard could be obtained and analysed. The proposed structure of TP 406 could be verified by a commercially available reference standard.
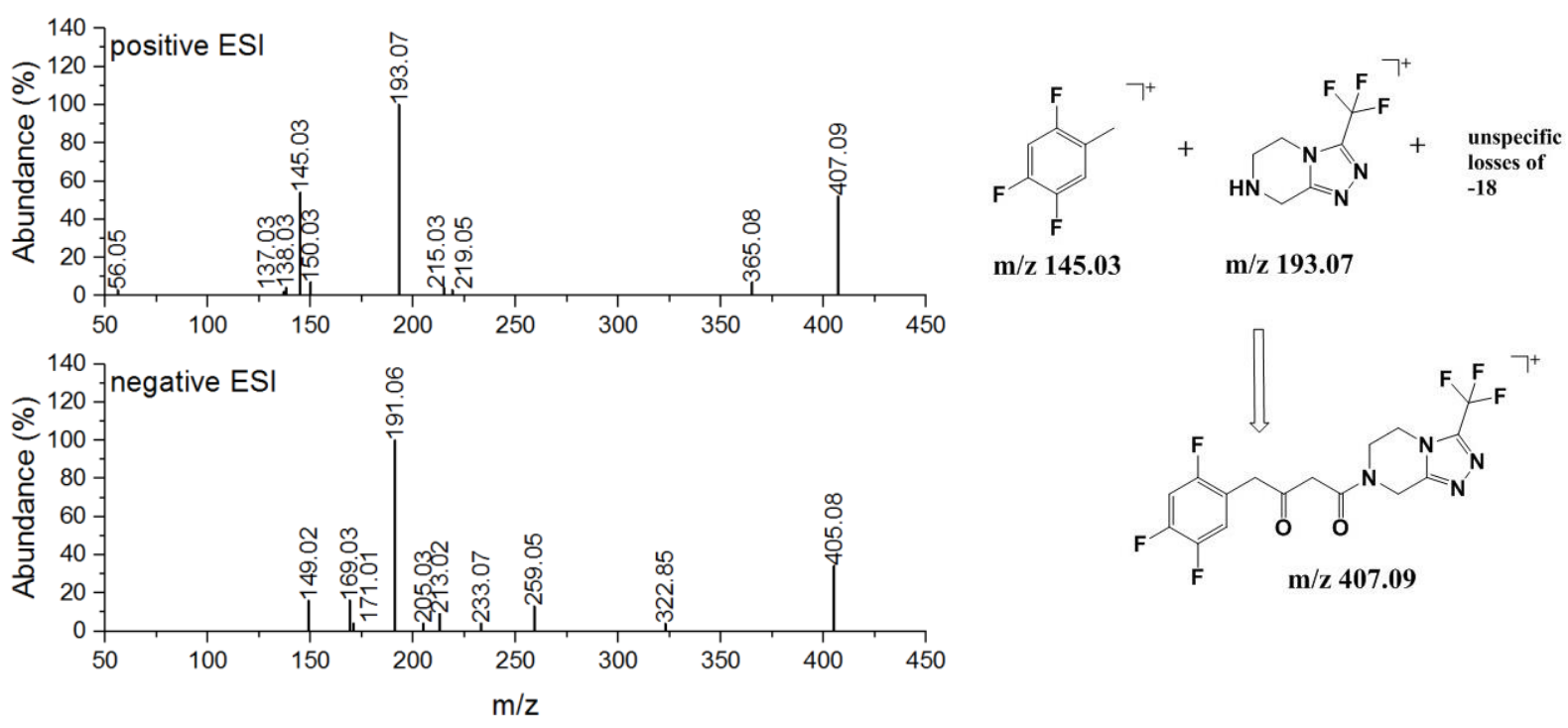

Figure S9. MS2 spectra of TP 406 in positive and negative ESI (left) and structure elucidation in positive ESI (right) 


\section{Supporting Information}

TP 192: TP 192 only can be detected in positive ESI and can be identified as the triazole-piperazine unit. Since a reference standard is available commercially, identification can be verified. The detected MS2 spectrum serves as comparison for the other detected TPs.
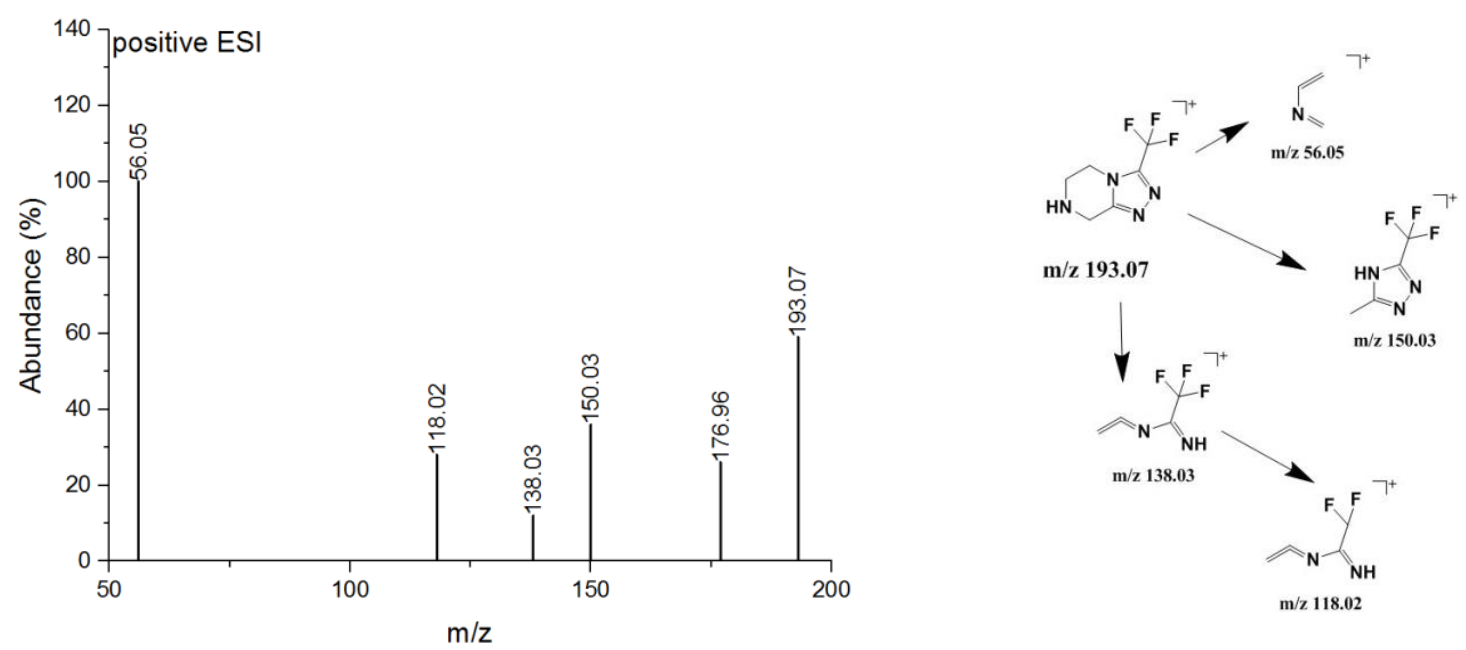

Figure S10. MS2 spectra of TP 192 in positive ESI (left) and characteristic fragments in positive ESI

$$
\text { (right) }
$$

TP 264: A specific loss of -44 could be observed which can be attributed to the loss of $\mathrm{CO} 2$ forming fragment $\mathrm{m} / \mathrm{z} 221.063$ in positive ESI. In positive ESI the fragments $\mathrm{m} / \mathrm{z} 193.07,150.03,138.03$, 118.02 and 56.05 can be attributed to the triazole-piperazine unit which seems to be unchanged. Thus, a carboxy group seems to be attached to the triazole-piperazine unit. The base peak of $\mathrm{m} / \mathrm{z}$ 191.06 can be assigned to the triazole-piperazine unit. As in pos ESI the quasi-molecular ion cannot be observed. A peak with exactly the same MS2 spectrum at the same exact mass was also obtained in IC-ESI-QTOF. Thus, the molecule contains a negative charge which corresponds to the observed loss of the carbonyl group. A search in MetFrag with the obtained MS2 data confirmed the structure, the molecular formula is C8H7F3N4O3.
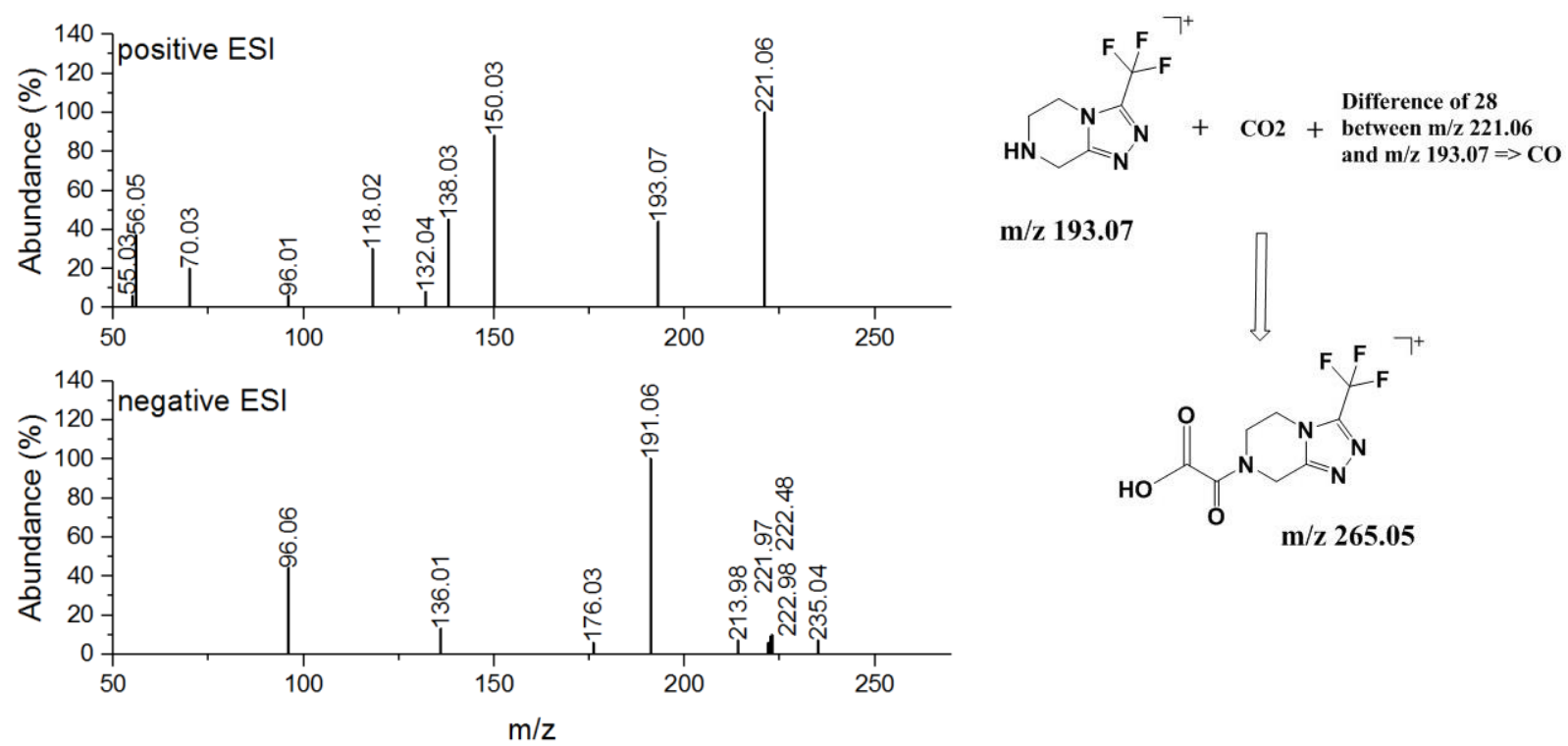

$\mathbf{m} / \mathbf{z} 193.07$

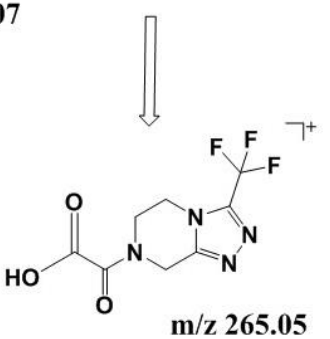

Figure S11. MS2 spectra of TP 264 in positive and negative ESI (left) and structure elucidation in positive ESI (right) 


\section{Supporting Information}

TP 206b: Fragments $\mathrm{m} / \mathrm{z} 138.03$ and $\mathrm{m} / \mathrm{z} 118.02$ are known as fragments of the triazole-piperazine unit (see at TP 192). However, since there is not the characteristic fragment of the triazolepiperazole unit itself, it seems to be altered upon transformation. An unspecific loss of of - 18 from the quasi-molecular ion, leading to a low intensity fragment mass, can be detected. Thus, an oxygen might be present in the structure. The MS2 spectrum of the negative ESI confirms that the triazolepiperazole unit must be altered since the characteristic fragment of $\mathrm{m} / \mathrm{z} 191.06$ is missing. Searching for possible molecular formulas by the exact mass gave $\mathrm{C} 6 \mathrm{H} 5 \mathrm{~F} 3 \mathrm{~N} 4 \mathrm{O}$ with a double bond equivalent of 5 as possible result. However, the proposed structure could not be verified, neither by a reference standard not by a search in MetFrag.
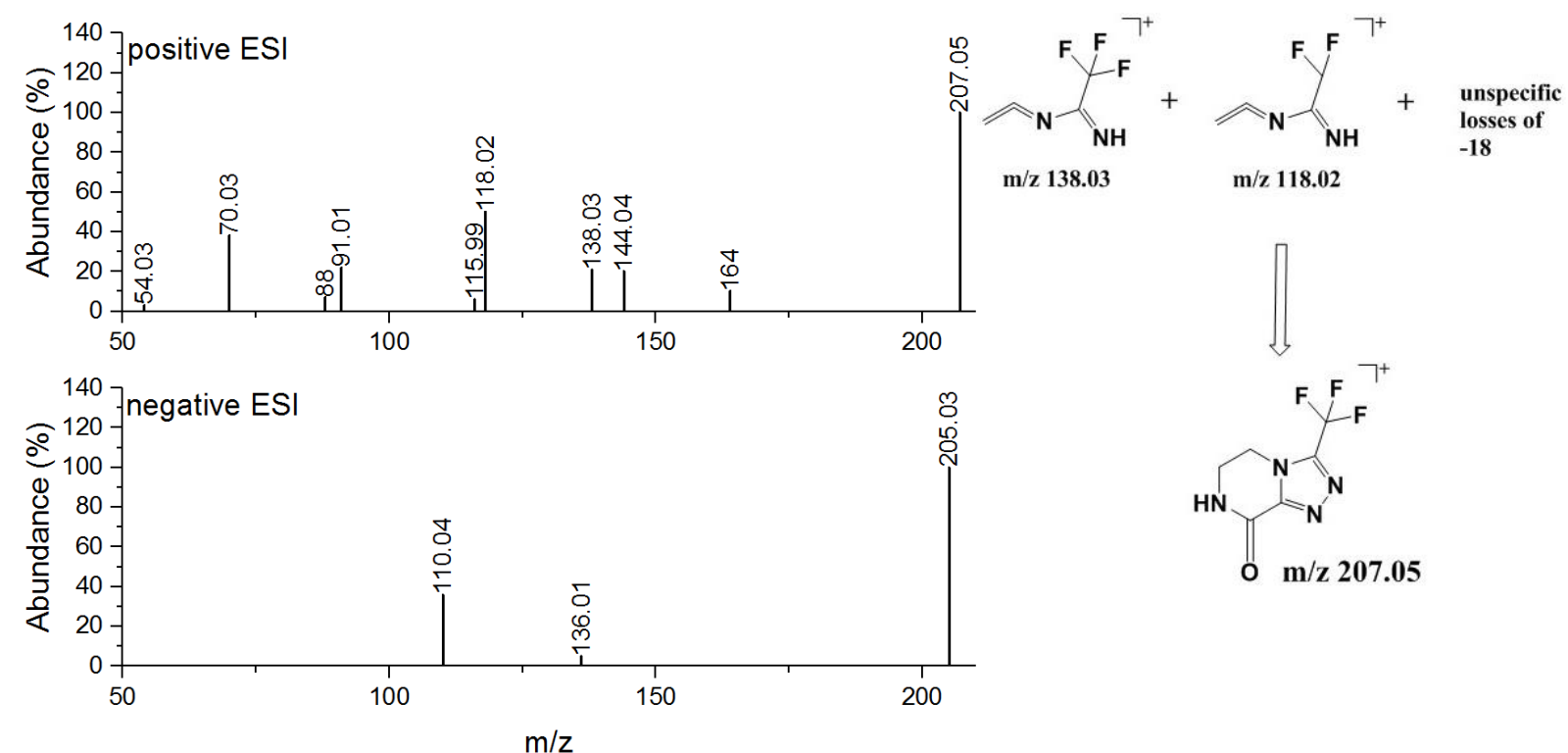

Figure S12. MS2 spectra of TP 206b in positive and negative ESI (left) and structure elucidation in positive ESI (right)

TP 421c: The MS2 spectrum of TP 421c in positive ESI contains characteristic fragments for the benzoyl unit ( $\mathrm{m} / \mathrm{z} 145.03$ ) as well as for the triazole-piperazine unit ( $\mathrm{m} / \mathrm{z}$ 193.07). Fragment $\mathrm{m} / \mathrm{z}$ 191.06 also appears as fragment of TP 437 and is thought to be also caused by the triazolepiperazine unit. In contrast to the MS2 spectrum of the positive ionization, the characteristic fragment for the triazole-piperazine unit is not visible in negative ionization. Base peak is $\mathrm{m} / \mathrm{z}$ 136.01. There is a series of fragments showing losses of $-20(\mathrm{~m} / \mathrm{z} 420.08 / 400.08$ and $377.08 / 357.08)$ which might be due to losses of HF. The exact mass leads to a proposed molecular formula of $\mathrm{C} 16 \mathrm{H} 13 \mathrm{~F} 6 \mathrm{~N} 5 \mathrm{O} 2$ with a double bond equivalent of 10 . TP 421c also could be detected by IC-ESIQTOF, thus, a TP must carry a negative charge at the $\mathrm{pH}$ of the mobile phase in IC $(\mathrm{pH}=10)$. This would fit to an oxime structure of STG. 


\section{Supporting Information}
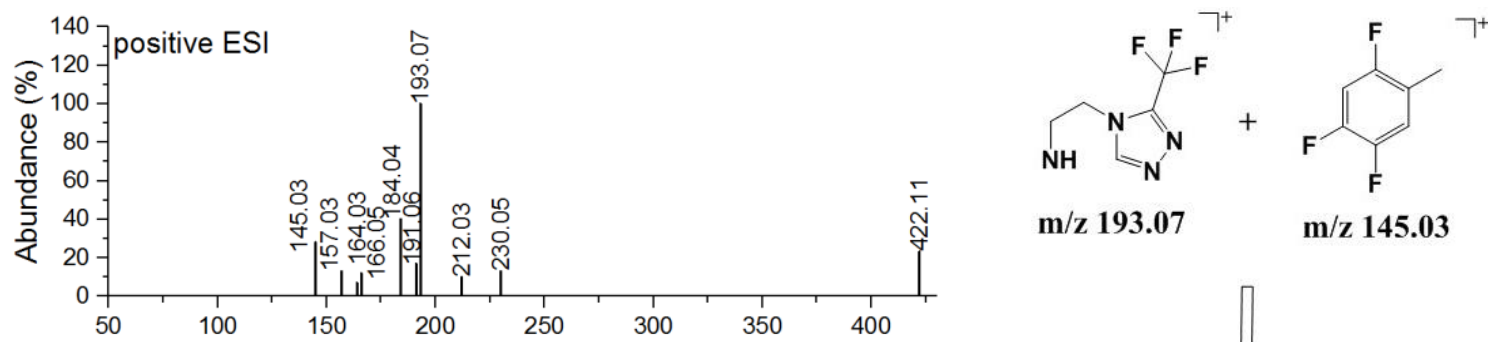

$\mathbf{m} / \mathbf{z} 193.07$

$\mathrm{m} / \mathrm{z} 145.03$

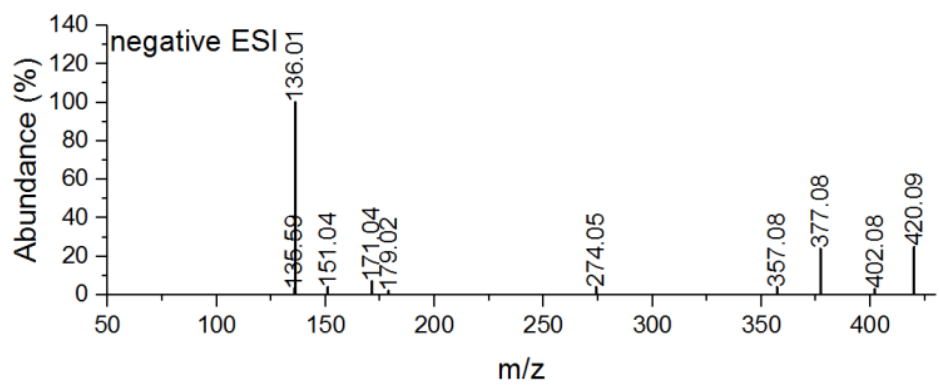<smiles>C=C=CCCCCCCCCCCCCCCCCCCCCCCC(=O)N1CCn2c(nnc2C(F)(F)F)C1</smiles>

$\mathrm{m} / \mathrm{z} 422.1$

Figure S13. MS2 spectra of TP 421c in positive and negative ESI (left) and structure elucidation in positive ESI (right)

TP 421 b: TP 421b shows a complex MS2 spectrum with several fragment masses. The spectrum differs from the ones obtained for TP 421a and 421c. The characteristic fragments for the triazolepiperazine unit cannot be observed, except for $\mathrm{m} / \mathrm{z}$ 150.03. But the characteristic fragments for the benzyol unit are present. Furthermore, fragment 199.04 is known from TP 437 and was assigned to the benzoyl unit. The high intensity of the $[\mathrm{M}+\mathrm{H}]+$ speaks for low fragmentability. The high mass range shows several fragments which makes assignment of neutral losses quite difficult. The MS2 spectrum in negative ESI is more clear than for positive ESI. Losses of -18 and -20 can be observed but there is still no precise information for structure elucidation. The exact mass leads to a proposed molecular formula of $\mathrm{C} 16 \mathrm{H} 13 \mathrm{~F} 6 \mathrm{~N} 5 \mathrm{O} 2$ with a double bond equivalent of 10 . However, a structure could not be proposed.
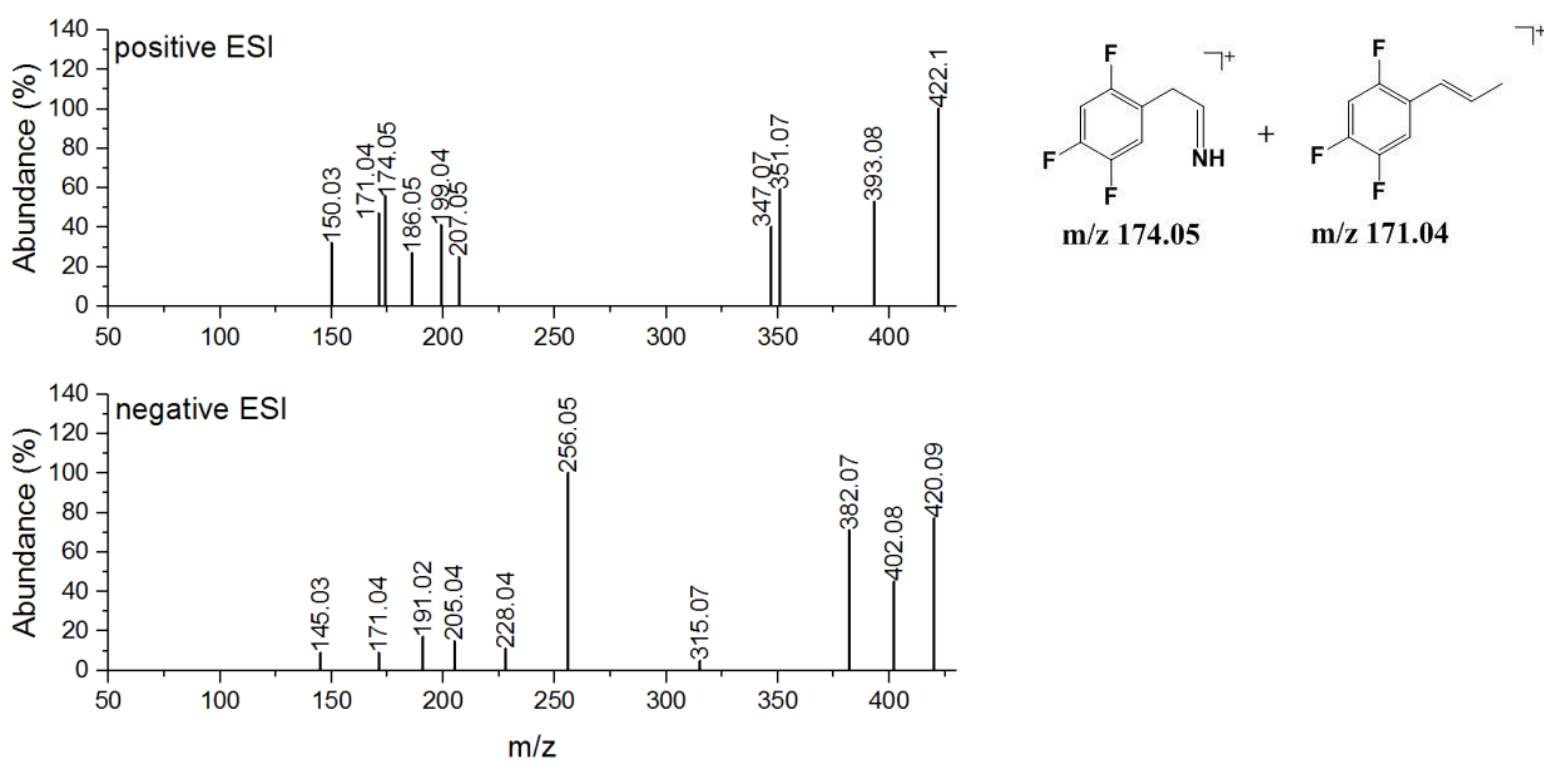

Figure S14. MS2 spectra of TP 421b in positive and negative ESI (left) and observed characteristic fragments in positive ESI (right) 


\section{Supporting Information}

TP 421a: The MS2 spectrum of TP 421a contains the characteristic fragment for the triazolepiperazine moiety, $\mathrm{m} / \mathrm{z} 191.05$ and $\mathrm{m} / \mathrm{z}$ 193.07. Characteristic fragments for the benzoyl moiety could not be identified. Base peak is $\mathrm{m} / \mathrm{z} 404.08$ which shows a loss of -18 to the quasi-molecular ion which is indicative for the addition of a. OH group to the molecule. In negative ESI higher intensities and MS2 spectra could be obtained. The high intensity for the [M-H)- shows the low fragmentability of the structure. The base peak, $\mathrm{m} / \mathrm{z} 329.09$, is nearly at the same height as the quasi-molecular ion. The characteristic fragment of the triazole-piperazine unit can be observed as well as losses of -47 and -44 . The exact mass leads to a proposed molecular formula of $\mathrm{C} 16 \mathrm{H} 13 \mathrm{~F} 6 \mathrm{~N} 5 \mathrm{O} 2$ with a double bond equivalent of 10 . However, a structure could not be proposed.
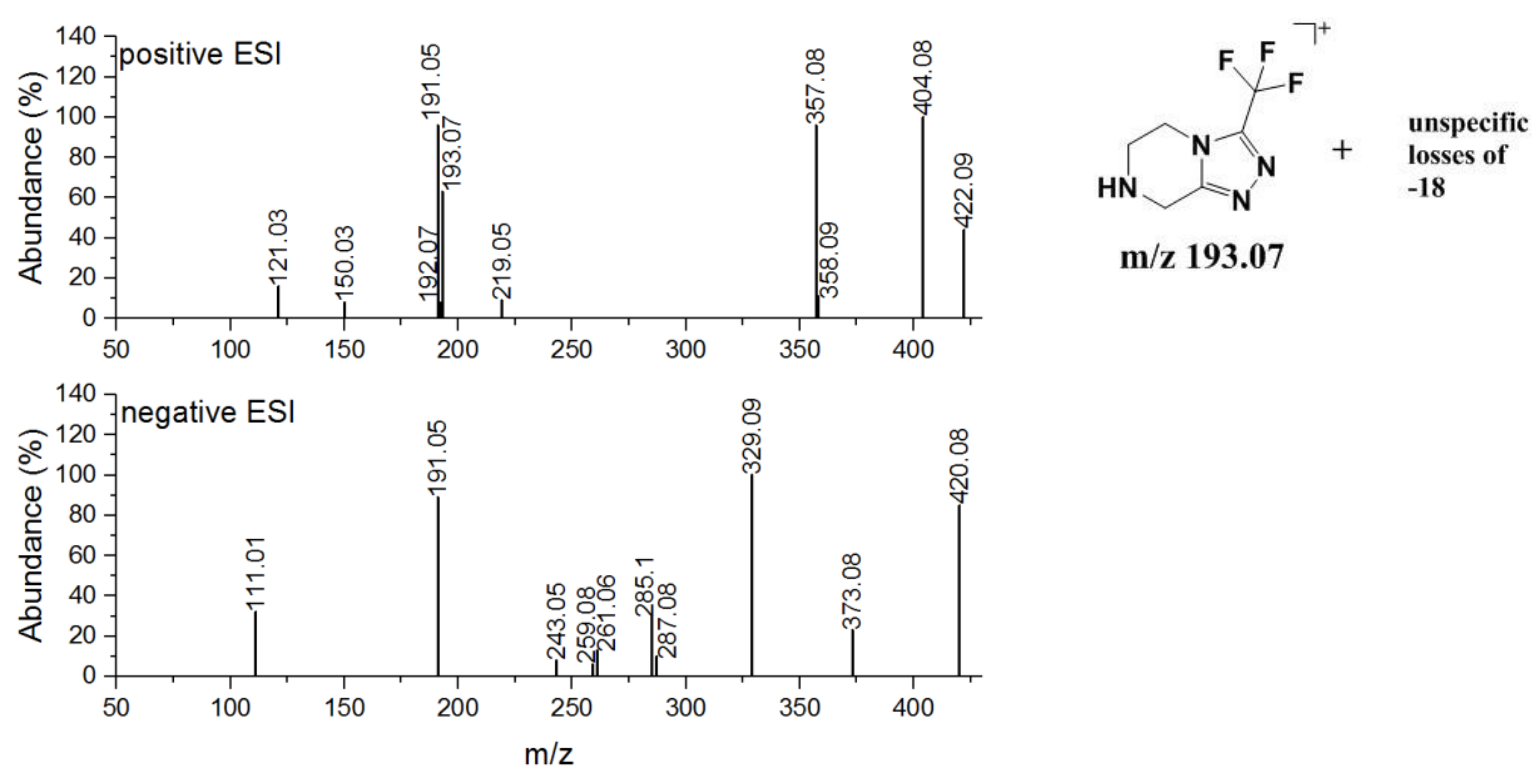

Figure S15. MS2 spectra of TP 421a in positive and negative ESI (left) and observed characteristic fragments in positive ESI (right)

TP 293: The MS2 spectrum of TP 293 shows the characteristic fragment for the triazole-piperazine unit ( $\mathrm{m} / \mathrm{z}$ 193.07) and fragments thereof ( $\mathrm{m} / \mathrm{z} 150.03,118.02$, additionally 138.02 and 56.05 as low intensity fragments). Highest mass fragments are $\mathrm{m} / \mathrm{z} 277.05(\Delta-17)$ and $\mathrm{m} / \mathrm{z} 276.07(\Delta-18)$, possibly showing a loss of $\mathrm{OH}$ and $\mathrm{H} 2 \mathrm{O}$ respectively. The MS2 spectrum of the negative ESI supports the assumption of the intact triazole-piperazine unit due to the presence of fragment $\mathrm{m} / \mathrm{z} 191.05$. The exact mass leads to a molecular formula of $\mathrm{C9H} 10 \mathrm{~F} 3 \mathrm{~N} 5 \mathrm{O} 3$ with a double bond equivalent of 6 . 


\section{Supporting Information}
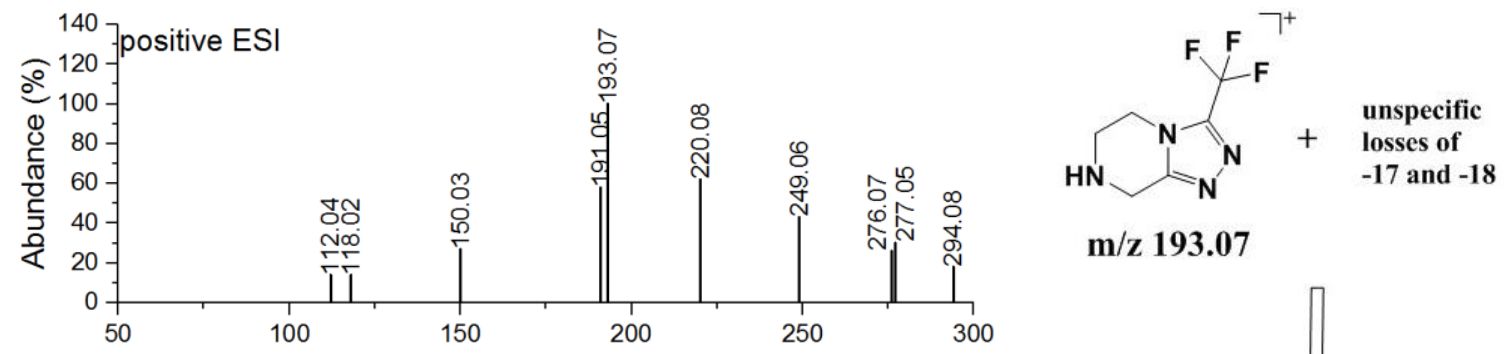

$\mathrm{m} / \mathbf{z} 193.07$<smiles>O=C(CC[N+](=O)[O-])N1CCn2c(nnc2C(F)(F)F)C1</smiles>

$\mathrm{m} / \mathrm{z} 294.08$

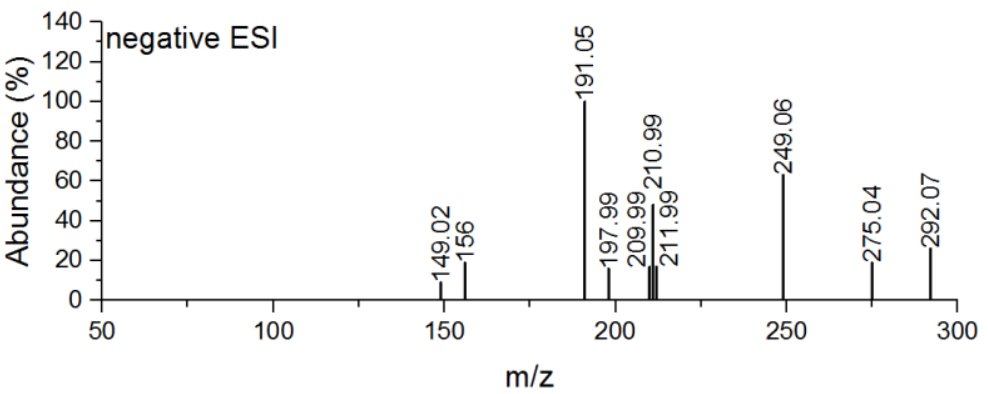

Figure S16. MS2 spectra of TP 293 in positive and negative ESI (left) and structure elucidation in positive ESI (right)

TP 453: In positive ESI the MS2 spectrum of TP 453 shows the characteristic fragments for the benzoyl unit ( $\mathrm{m} / \mathrm{z} 171.04,151.04,145.03)$. The fragment $\mathrm{m} / \mathrm{z} 191.05$ is known from the MS2 spectrum of TP 437 and can be assigned to the triazole-piperazine unit. The spectrum shows a loss of -47 to a low intensity fragment and a further loss of -18 , yielding $\mathrm{m} / \mathrm{z} 389.09$. Thus, the molecule contains a nitro group and an additional Hydroxyl-Group. In negative ESI again the loss of the nitro group ( $\mathrm{m} / \mathrm{z} 452.08$ to $\mathrm{m} / \mathrm{z} 405.08$ ) can be observed, giving the base peak of the spectrum. Also the loss of -18 occurs, yielding $\mathrm{m} / \mathrm{z}$ 387.07. By the exact mass a molecular formula of C16H13F6N5O4 with a double bond equivalent of 9 was derived.
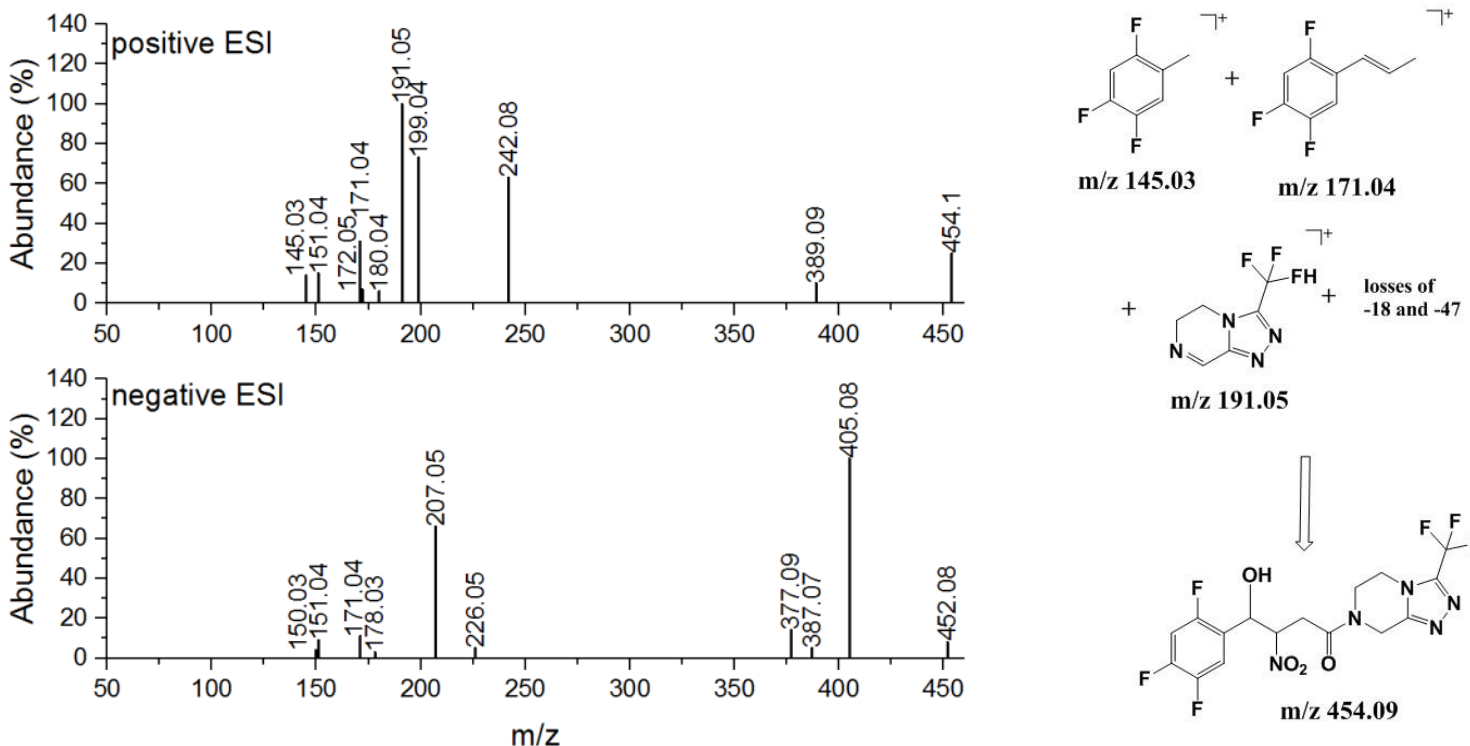

$\mathrm{m} / \mathrm{z} 191.05$

Figure S17. MS2 spectra of TP 453 in positive and negative ESI (left) and structure elucidation in positive ESI (right) 


\section{Supporting Information}

TP 390: For TP 390 characteristic fragments for the benzoyl unit $(\mathrm{m} / \mathrm{z} 171.04)$ as well as for the triazole-piperazine unit ( $\mathrm{m} / \mathrm{z}$ 193.07) could be observed. The same exact mass also can be detected as fragment for STG and TP 437 but TP 390 shows a different RT and therefor also is formed as original TP. The MS2 spectrum of the negative ESI supports the assumption of the intact triazolepiperazine unit due to the presence of fragment $\mathrm{m} / \mathrm{z} 191.05$. By the exact mass a molecular formula of $\mathrm{C} 16 \mathrm{H} 12 \mathrm{~F} 6 \mathrm{~N} 4 \mathrm{O}$ with a double bond equivalent of 10 was derived.
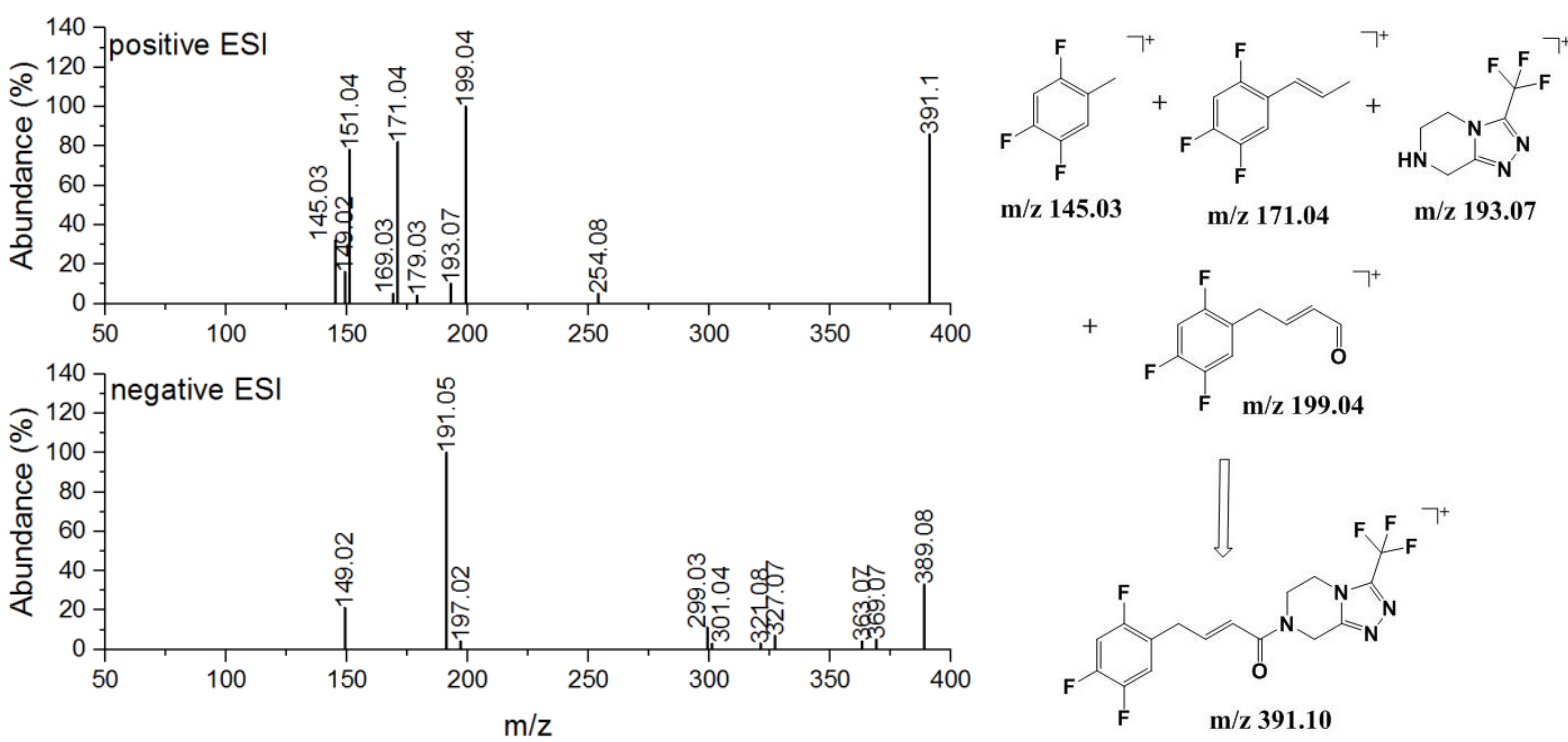

Figure S18. MS2 spectra of TP 390 in positive and negative ESI (left) and structure elucidation in positive ESI (right)

TP 310: The MS2 spectrum of positive ESI shows a high number of fragment masses with similar intensity. Characteristic fragments for the triazole-piperazine unit can be observed but a structure elucidation is not possible.

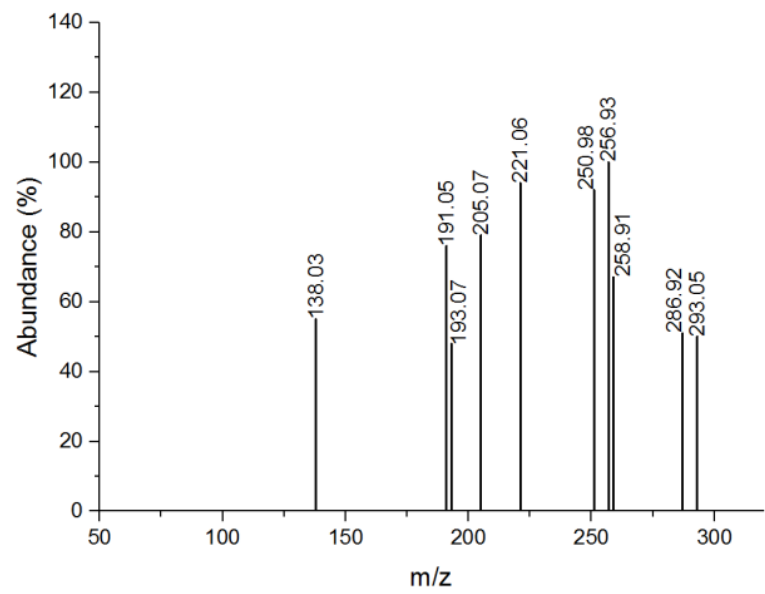

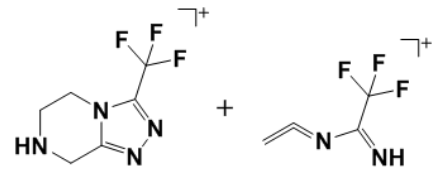

$\mathrm{m} / \mathbf{z} 193.07 \quad \mathrm{~m} / \mathbf{z} \mathbf{1 3 8 . 0 3}$

Figure S19. MS2 spectra of TP 310 in positive ESI (left) and observed characteristic fragments (right)

TP 252: The MS2 spectrum of TP 252 in positive ESI does not show any characteristic fragments for the STG structure. In addition, no specific losses can be observed. However, the fact that the $[\mathrm{M}+\mathrm{H}]+$ is not visible speaks for an easily cleaved group within the structure. Also negative ESI does not lead to already known characteristic fragments. Here, the quasi-molecular ion is visible, base peak is the fragment $\mathrm{m} / \mathrm{z} 210.99$ (loss of -40 ). However, a structure elucidation is not possible. 

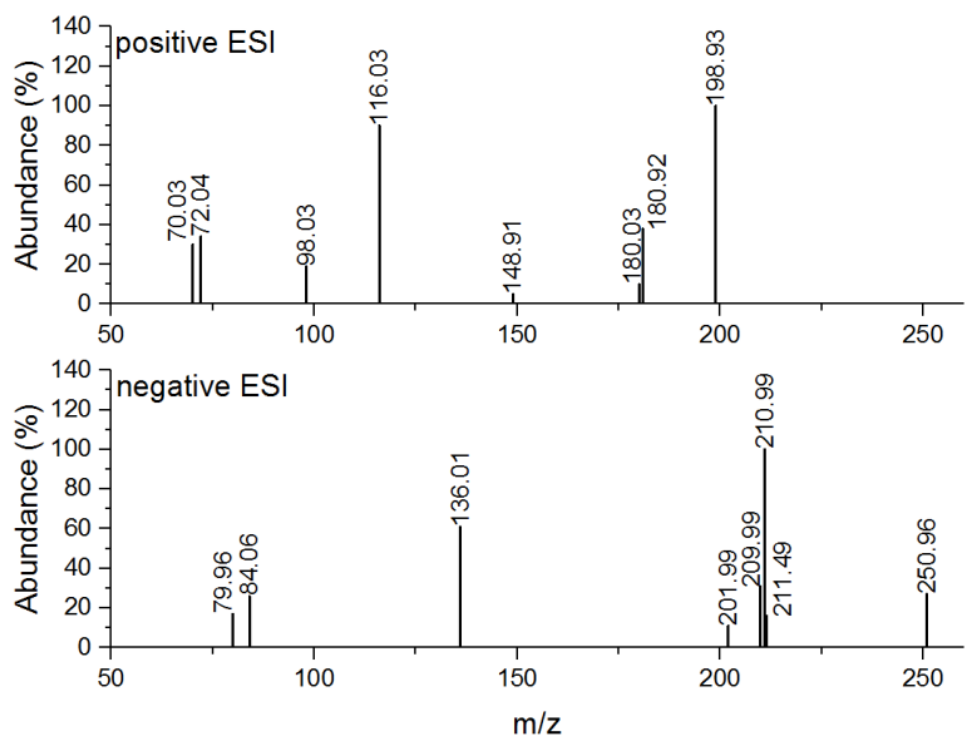

Figure S20. MS2 spectra of TP 252 in positive and negative ESI

TP 254: As for TP 252 neither characteristic fragments nor specific losses can be observed in the MS2 spectrum of TP 254. Although also the MS2 spectrum in negative ESI does not show any characteristic fragments, it does show a fragment also occurring at TP 252: $\mathrm{m} / \mathrm{z}$ 136.01. This fragment also occurs for other TPs and might show some structural similarities. A structure for TP 254 cannot be proposed.
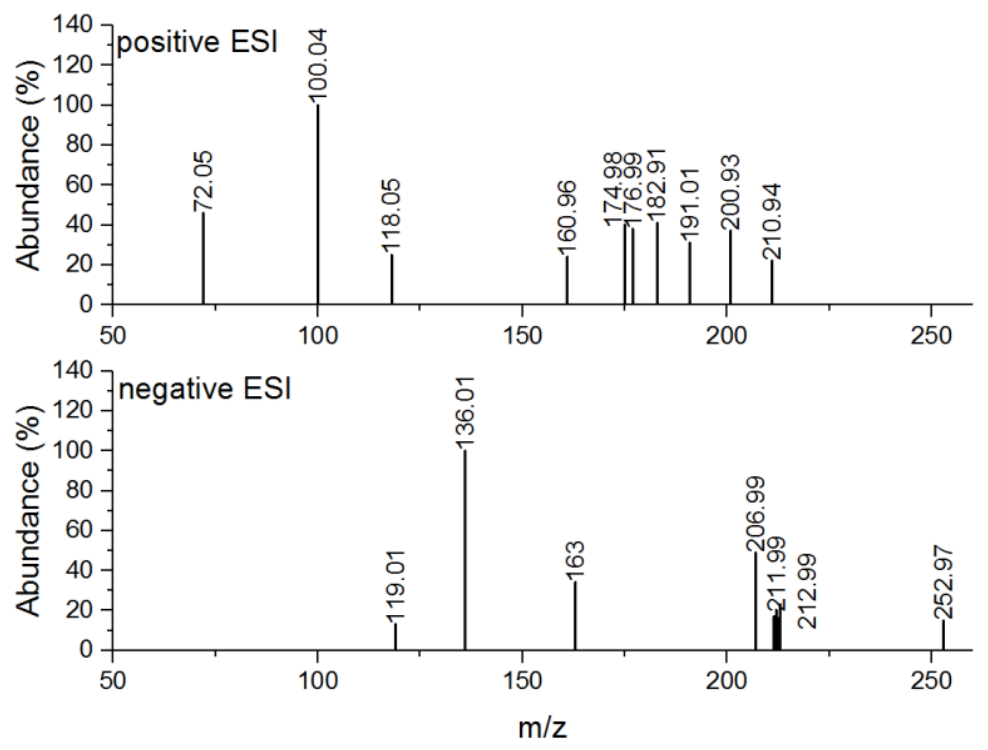

Figure S21. MS2 spectra of TP 254 in positive and negative ESI

TP 294: Since all characteristic fragments for the triazole-piperazine unit can be observed for TP 294, this part must be unchanged. In addition, no quasi-molecular ion is observed, speaking for an easy to cleave group, and a specific loss of -44 occurred from the precursor mass to the highest mass fragment of $\mathrm{m} / \mathrm{z} 251.07$, being assigned to a loss of $\mathrm{CO} 2$. Further, an unspecific loss of -18 can be observed from $\mathrm{m} / \mathrm{z} 251.07$ to $\mathrm{m} / \mathrm{z} 233.06$. Both losses together might be an indication for three oxygen atoms in the molecule. The uneven mass of the precursor speaks for an even number of nitrogens. Base peak of the MS2 in negative ESI is fragment $\mathrm{m} / \mathrm{z} 191.06$ which corresponds to the 


\section{Supporting Information}

triazole-piperazine unit, confirming its unchanged presence in the molecule. A structure for TP 294 cannot be proposed.
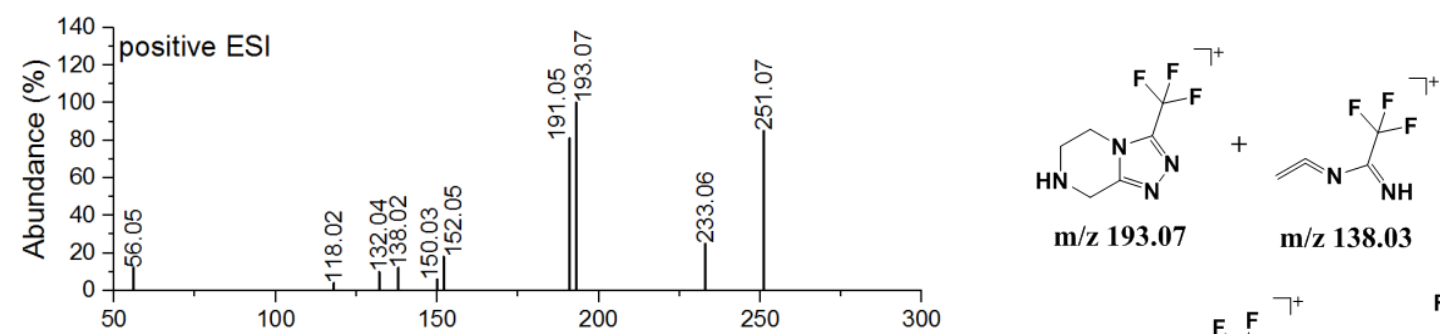

$\mathrm{m} / \mathrm{z} 193.07 \quad \mathrm{~m} / \mathrm{z} \mathbf{1 3 8 . 0 3}$
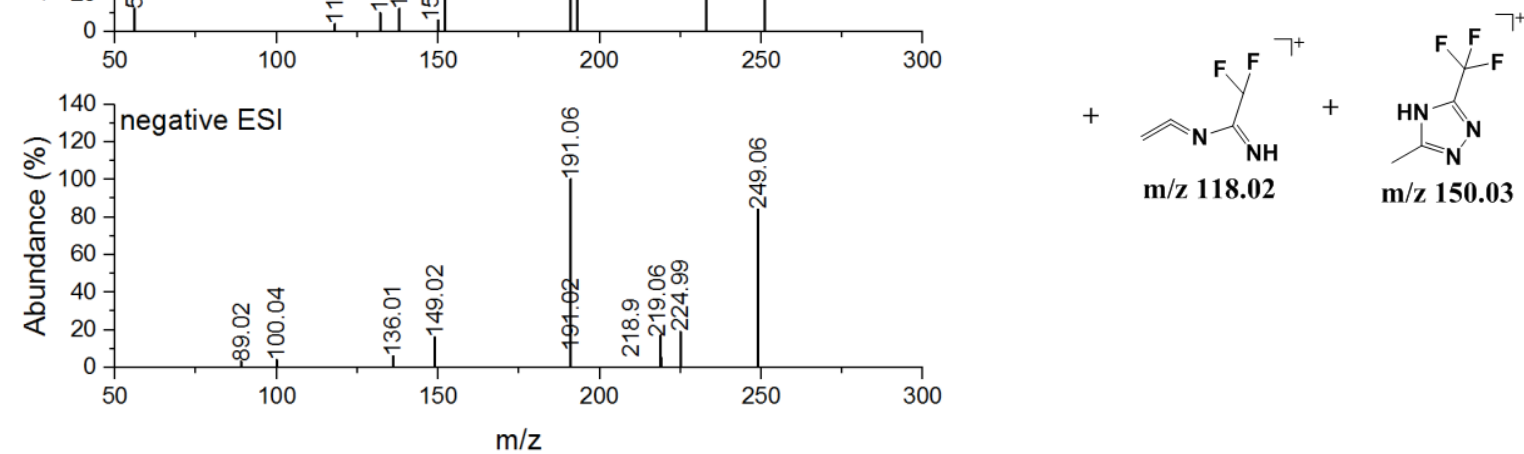

Figure S22. MS2 spectra of TP 294 in positive and negative ESI (left) and observed characteristic fragments (right)

TP 379: In positive ESI the quasi-molecular ion is not visible. The mass difference to the highest mass fragment $\mathrm{m} / \mathrm{z} 336.09$ is -44 , which usually can be assigned to $\mathrm{CO} 2$. Furthermore, unspecific losses of -18 and -28 were observed, possibly showing another oxygen atom. The even $\mathrm{m} / \mathrm{z}$ of the precursor indicated an uneven number of nitrogens and the triazole-piperazine unit is unchanged due to the appearance of the characteristic fragment $\mathrm{m} / \mathrm{z}$ 193.07. The MS2 of the negative ionization supports the assumption of the unchanged triazole-piperazine unit since the characteristic fragment $\mathrm{m} / \mathrm{z}$ 191.05 occurs in the spectrum. A structure for TP 379 cannot be proposed.
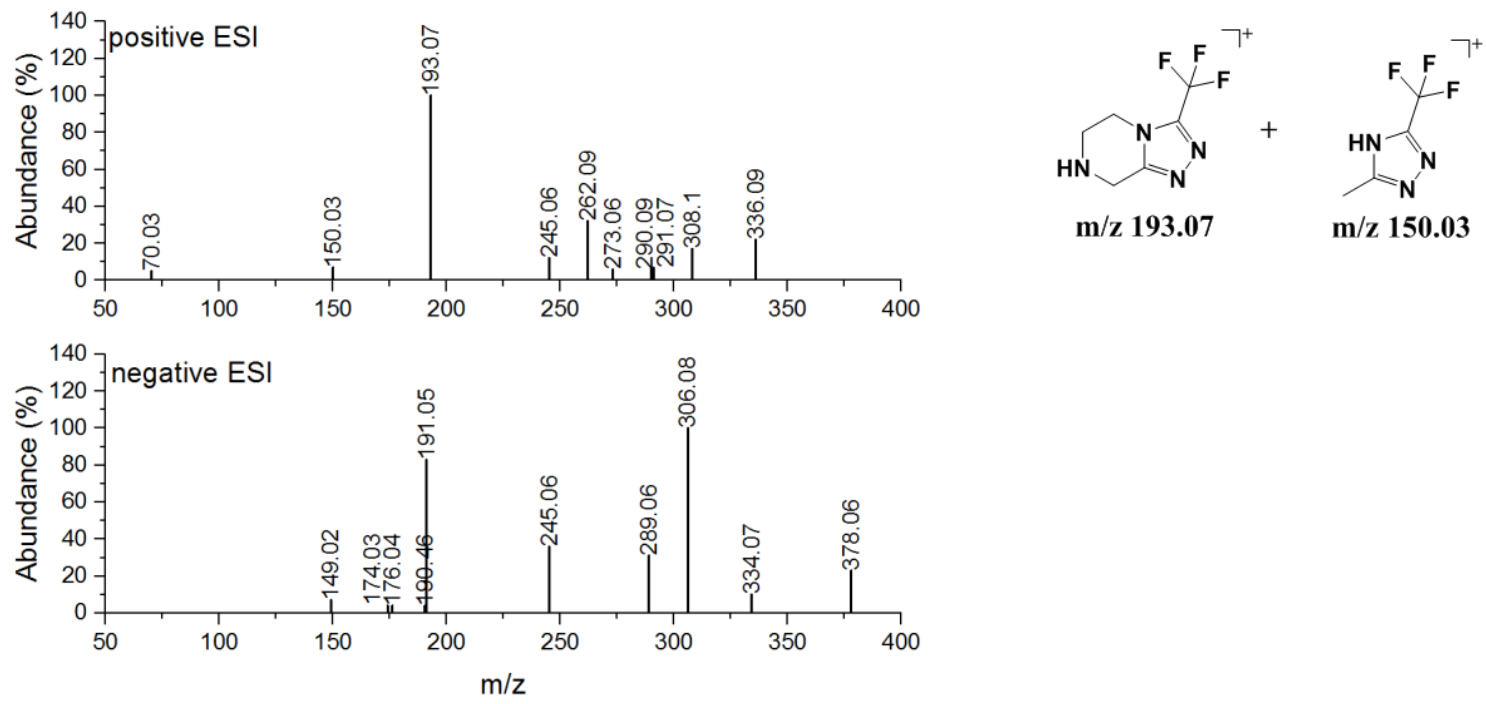

Figure S23. MS2 spectra of TP 379 in positive and negative ESI (left) and observed characteristic fragments in positive ESI (right)

TP 363: The MS2 spectrum of TP 363 does not contain any characteristic fragments. The high mass difference of -105 from the $[\mathrm{M}+\mathrm{H}]+$ to the highest mass fragment does not allow for any assumption about neutral losses. As for positive ESI, no characteristic fragments were visible in negative ESI. 


\section{Supporting Information}

Here, a lower mass difference from the quasi-molecular ion to the highest mass fragment of -18 could be observed. However, this does not lead to any further conclusions about a possible structure. A structure for TP 363 cannot be proposed.
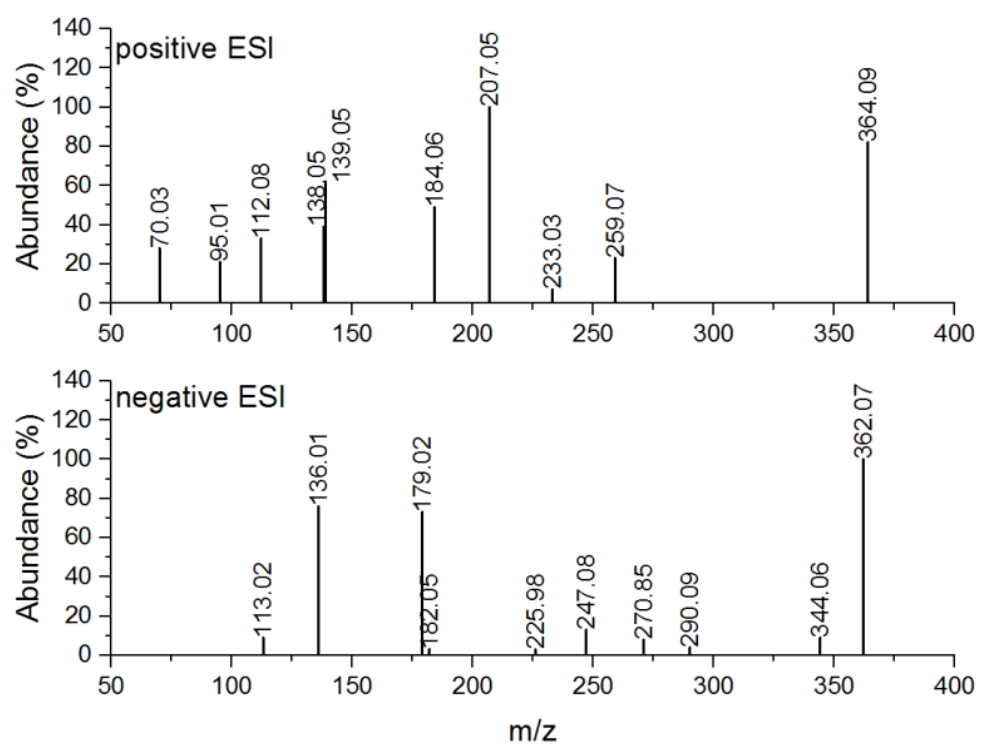

Figure S24. MS2 spectra of TP 363 in positive and negative ESI

TP 266: TP 266 shows all characteristic fragments for the triazole-piperazine unit in the $\mathrm{MS}^{2}$ spectrum of positive ESI. Furthermore, a mass difference of -18 was detected from the $[\mathrm{M}+\mathrm{H}]^{+}$to the highest mass fragment, $\mathrm{m} / \mathrm{z} 249.06$, a loss of -28 to fragment $\mathrm{m} / \mathrm{z} 221.07$ and a further loss of -28 to $\mathrm{m} / \mathrm{z}$ 193.07. A similar pattern of fragments already could be observed for TP 264 , the carboxylated triazole-piperazine unit. The facts that no specific loss of $\mathrm{CO} 2$ but an unspecific loss of $\mathrm{H} 2 \mathrm{O}$ could be observed and the difference of +2 between the TP masses might indicate basically the same structure, however, a signal for this TP could neither be detected in LC-ESI(neg)-QTOF nor in IC-ESIQTOF. By the exact mass a molecular formula of C8H9F3N4O3 was derived.
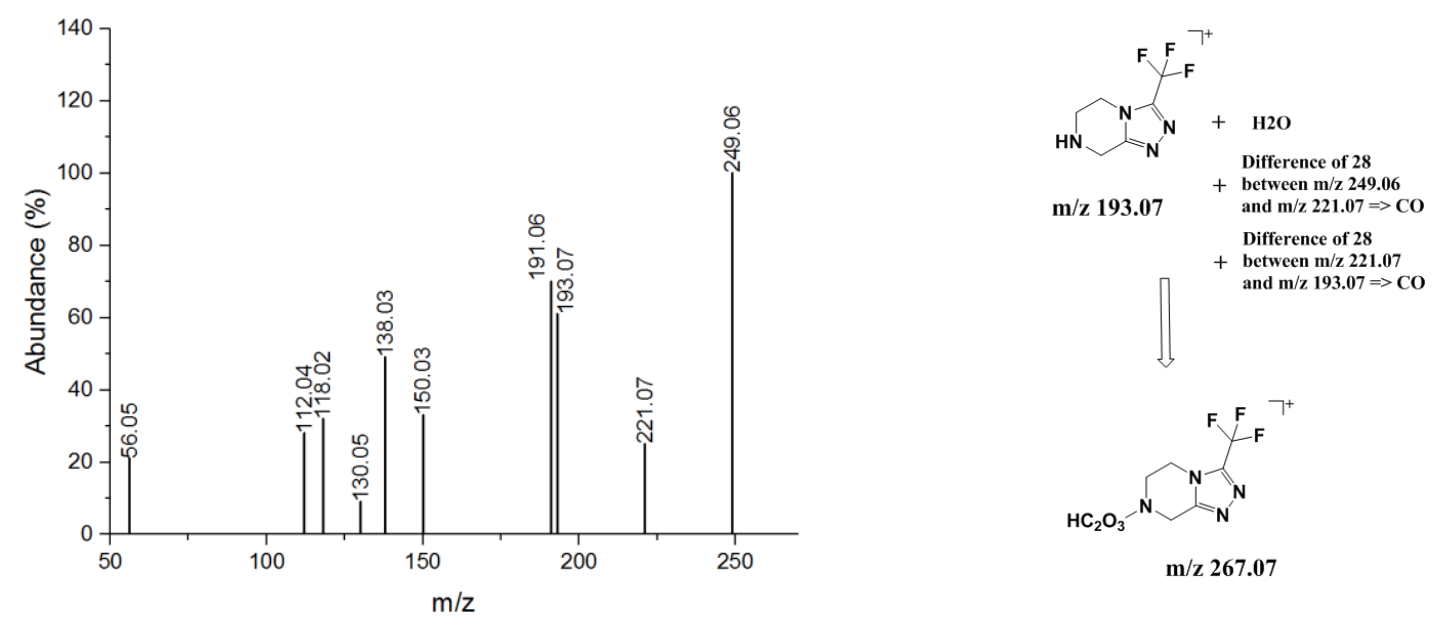

Figure S25. MS2 spectra of TP 266 in positive ESI (left) and structure elucidation for positive ESI (right)

TP 206a: The MS2 spectrum of positive ESI shows characteristic fragments of the triazole-piperazine unit, but fragment $\mathrm{m} / \mathrm{z} 193.07$ is missing. Therefore, alteration at this structure might have occurred. 


\section{Supporting Information}

Based on the exact mass the same molecular formula as well as the same structure as for TP 206a can be proposed. However, there are clear differences in the MS2 spectra of both and thus, the true structure of both TPs remains unclear. In negative ESI only three fragments can be observed with which no structure elucidation can be performed.
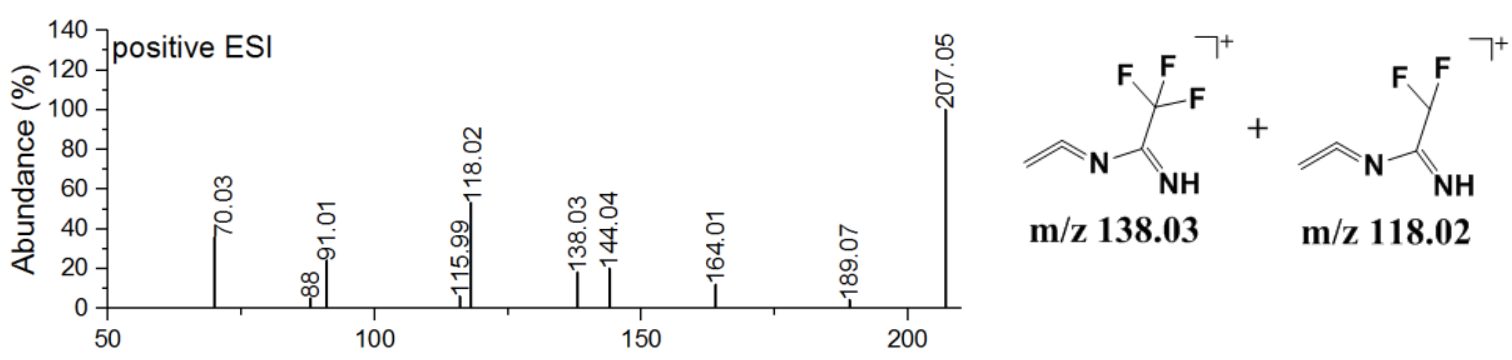

$\mathbf{m} / \mathbf{z} \mathbf{1 3 8 . 0 3} \quad \mathrm{m} / \mathbf{z} \mathbf{1 1 8 . 0 2}$

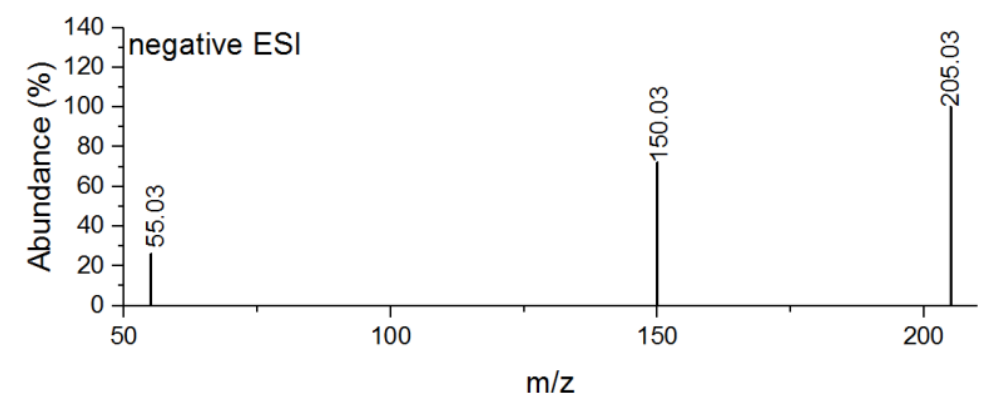

Figure S26. MS2 spectra of TP 206a in positive and negative ESI (left) and characteristic fragments in positive ESI (right)

TP 393: The MS2 spectrum of positive ESI for TP 393 contains the characteristic fragment for the triazole-piperazine unit ( $\mathrm{m} / \mathrm{z} 193.07)$ as well as fragments thereof at low intensity. Fragment $\mathrm{m} / \mathrm{z}$ 235.08 appears also for STG and shows the triazole-piperazine unit with the intact amide group. The presence of the triazole-piperazine unit in TP 393 is supported by the fragment $\mathrm{m} / \mathrm{z} 191.06$ in negative ESI. However, it is not the base peak of the spectrum but the second highest after $\mathrm{m} / \mathrm{z}$ 259.08. A structure for TP 393 cannot be proposed.
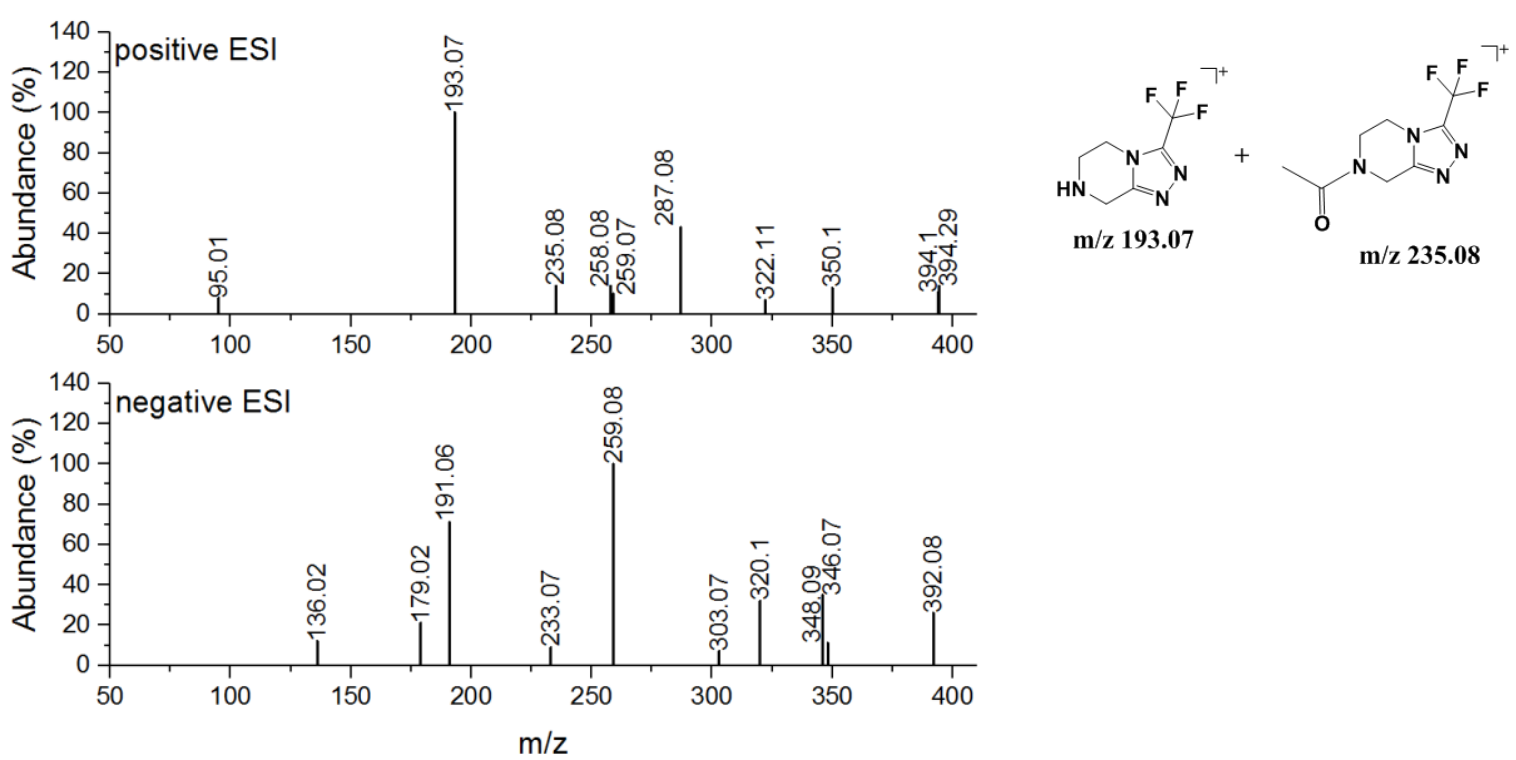

Figure S27. MS2 spectra of TP 393 in positive and negative ESI (left) and characteristic fragments in positive ESI (right) 


\section{Supporting Information}

TP 288: The MS2 spectrum of TP 228 in positive ESI does not contain any characteristic fragments. Base peak is the quasi-molecular ion, thus, there is no functional group which would be easy to cleave off. The mass difference of the $[\mathrm{M}+\mathrm{H}]+$ to the highest mass fragment $\mathrm{m} / \mathrm{z} 169.91$ is 60 which usually can be found in ester compounds ${ }^{3}$. It could not be detected in negative ESI. A structure for TP 288 could not be proposed.

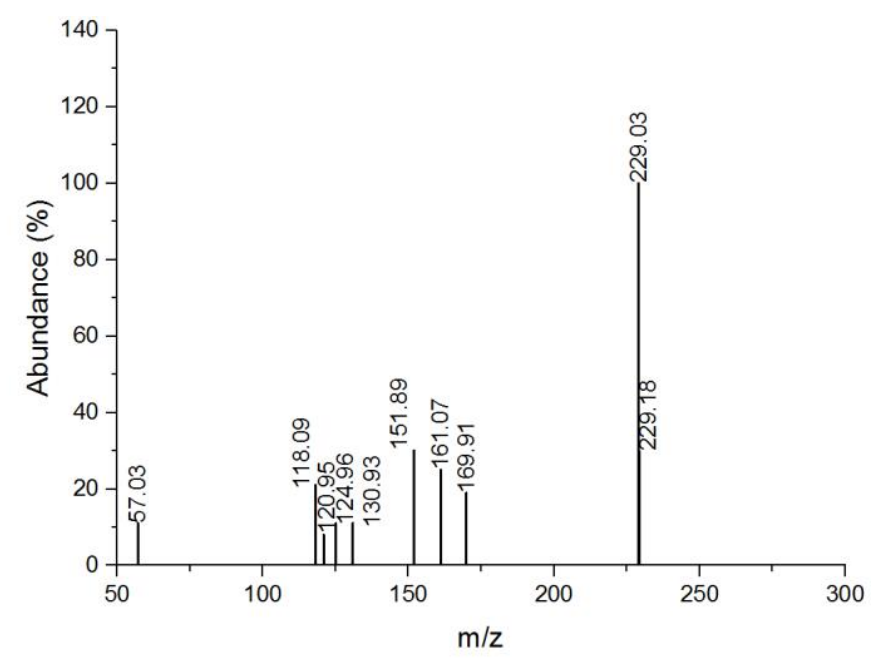

Figure S28. MS2 spectrum of TP 288 in positive ESI

TP 244: For TP 244 no characteristic fragments could be observed in the MS2 spectrum of positive ESI and it could not be detected in negative ESI.

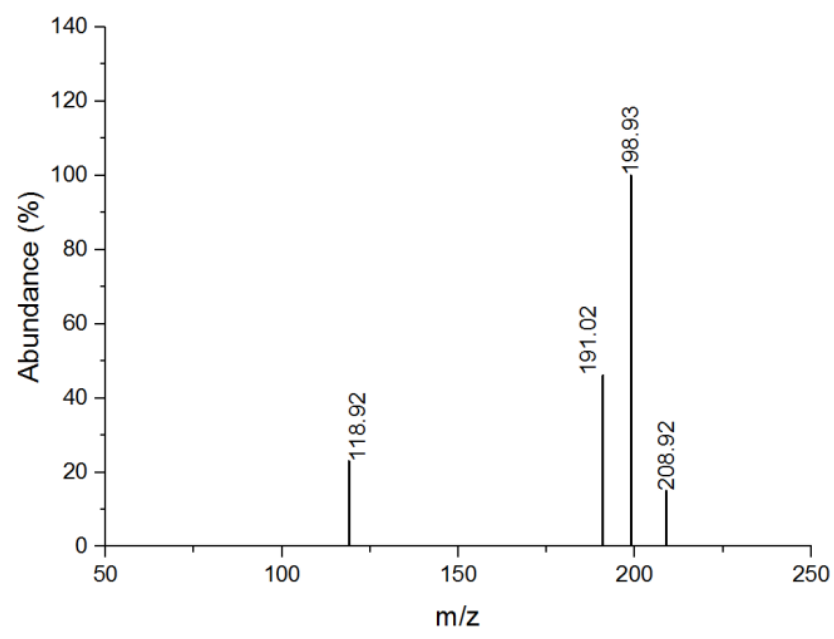

Figure S29. MS2 spectrum of TP 244 in positive ESI

TP 335: Characteristic fragments do not occur in the MS2 spectrum of positive ESI. However, base peak is 207.06 which might be the structure of TP $206 \mathrm{a}$ and/or $\mathrm{b}$. Furthermore there is an unspecific loss of $-18(\mathrm{H} 2 \mathrm{O})$ from the $[\mathrm{M}+\mathrm{H}]+$ to a low intensity fragment $(\mathrm{m} / \mathrm{z} 318.08)$. Further losses of -18 occur as well as a -42 . Base peak in negative ESI is $\mathrm{m} / \mathrm{z} 205.03$ which, as in positive ESI, might correspond with the structure of TP 206 a and/or b. 


\section{Supporting Information}

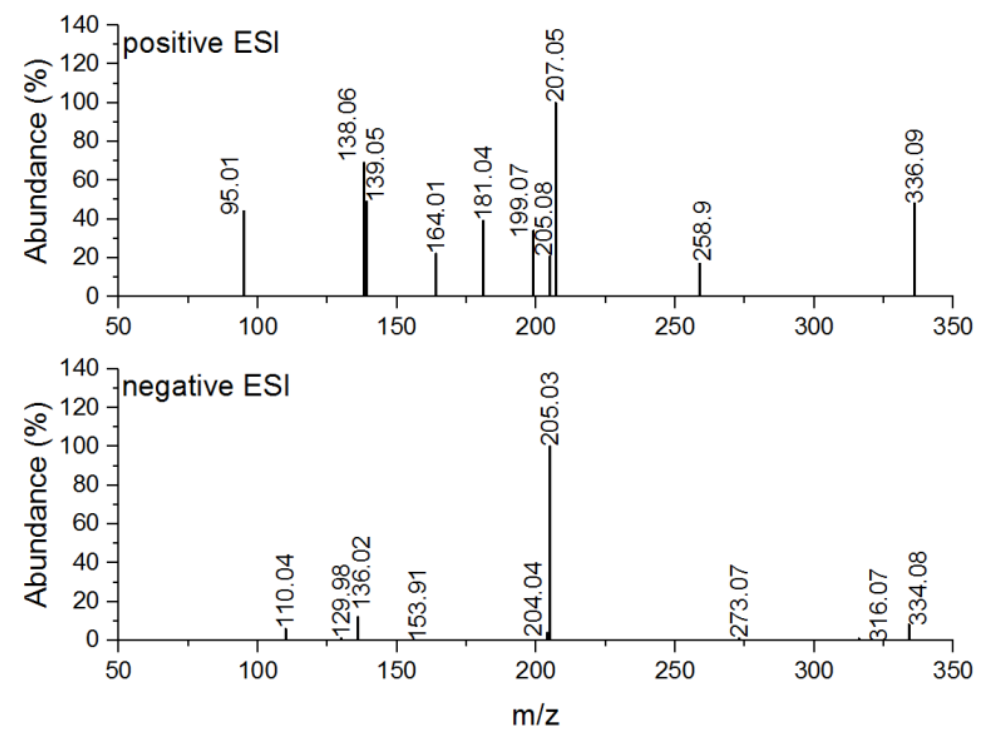

Figure S30. MS2 spectra of TP 335 in positive and negative ESI

TP 278: For TP 278 the characteristic fragments for the triazole-piperazine unit are observable as well as the fragment for the intact amide group ( $\mathrm{m} / \mathrm{z} 235.08)$. A loss of -18 can be observed from the $[M+H]+$ to give fragment $\mathrm{m} / \mathrm{z} 261.06$, followed by a -26 loss to fragment $\mathrm{m} / \mathrm{z} 235.08$.
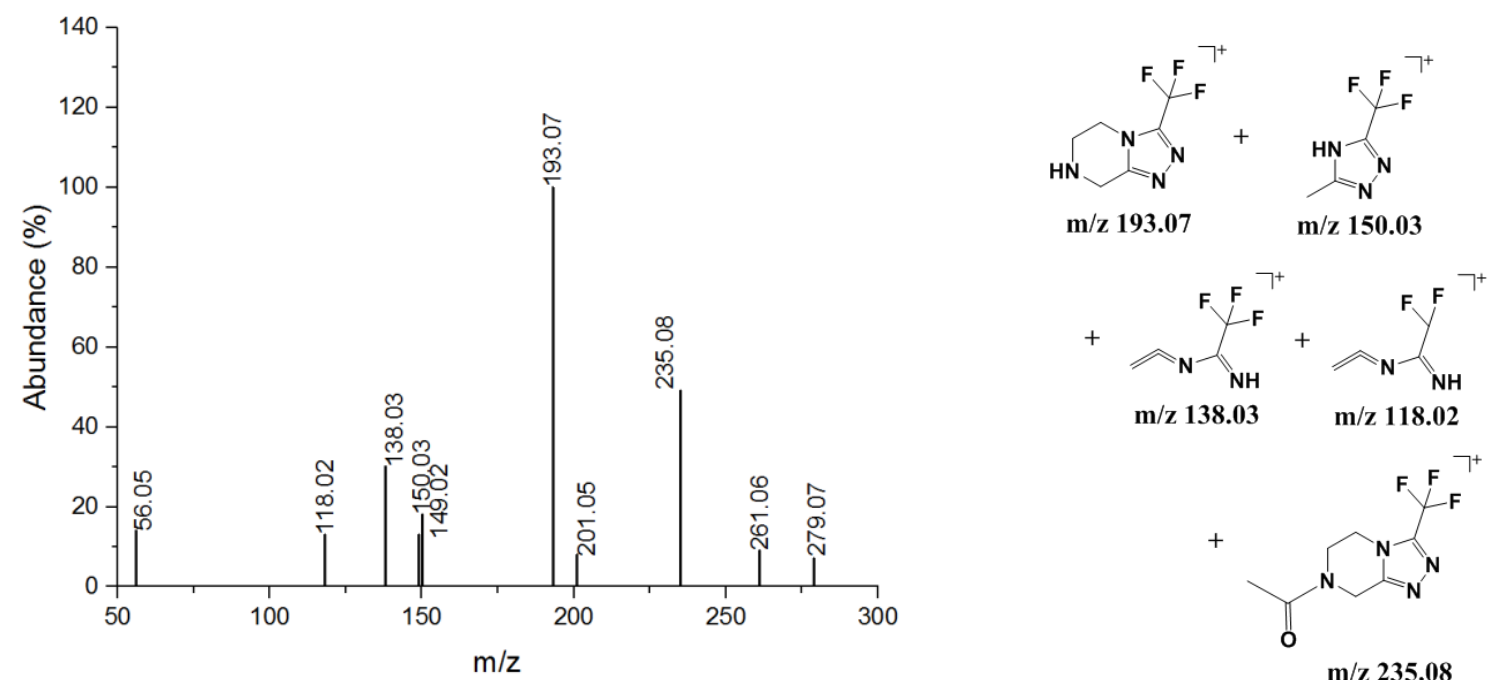

$\mathrm{m} / \mathrm{z} \mathbf{1 3 8 . 0 3} \mathrm{m} / \mathrm{z} \mathbf{1 1 8 . 0 2}$

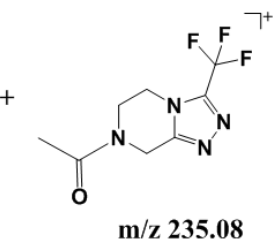

Figure S31. MS2 spectrum of TP 278 in positive ESI (left) and characteristic fragments ESI (right)

TP 339: TP 339 does not show any characteristic fragments in its positive ESI MS2 spectrum. Base peak is $\mathrm{m} / \mathrm{z} 156.07$ which does not appear as base peak in any other TP. The quasi-molecular ion cannot be observed, speaking for a high fragmentability but nearly no fragments can be observed in the higher mass region which is important for structure elucidation. In negative ESI base peak is $\mathrm{m} / \mathrm{z}$ 136.01. This fragment already could be observed for other TPs in negative ESI (e.g. TP 363, 254, 252). Furthermore a loss of -47 appears from the [M-H]- to m/z 291.01 followed by a loss of -44 to $\mathrm{m} / \mathrm{z}$ 247.08. However, also from negative ESI no precise information about a possible structure can be derived. 

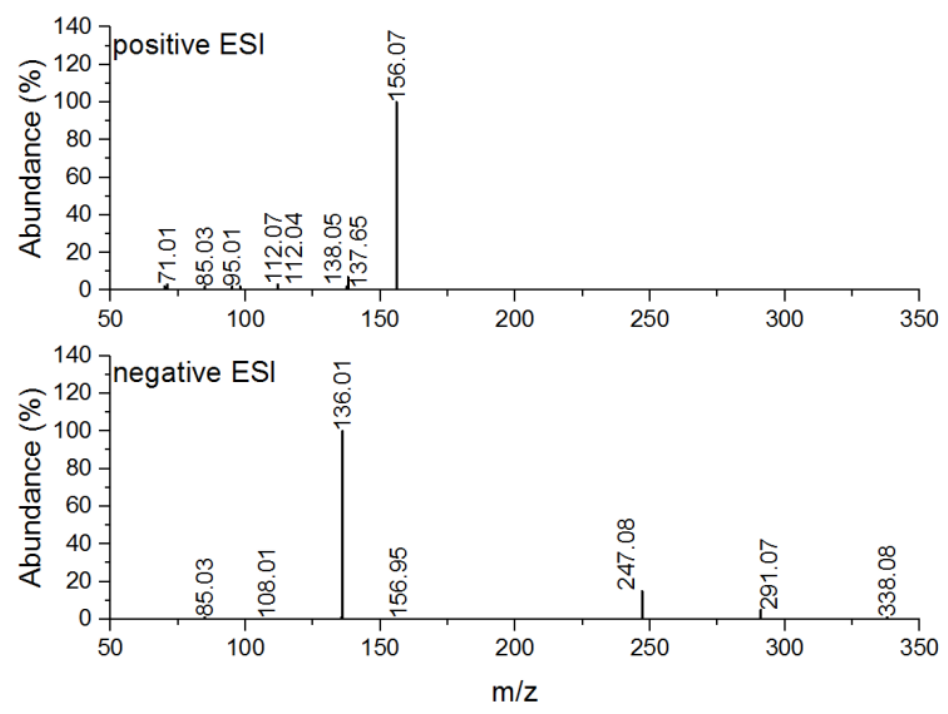

Figure S32. MS2 spectrum of TP 339 in positive and negative ESI

TP 343: TP 343 occurs only at a very low intensity in the ozonated samples. In positive ESI no MS2 was recorded. In negative ESI detected intensities were higher than in positive mode and a MS2 was recorded. As base peak it showed $\mathrm{m} / \mathrm{z} 191.06$ which is characteristic for the triazole-piperazine unit. The quasi-molecular ion could be observed, highest mass fragments show only little intensity. However, losses of -18 and -46 could be observed.

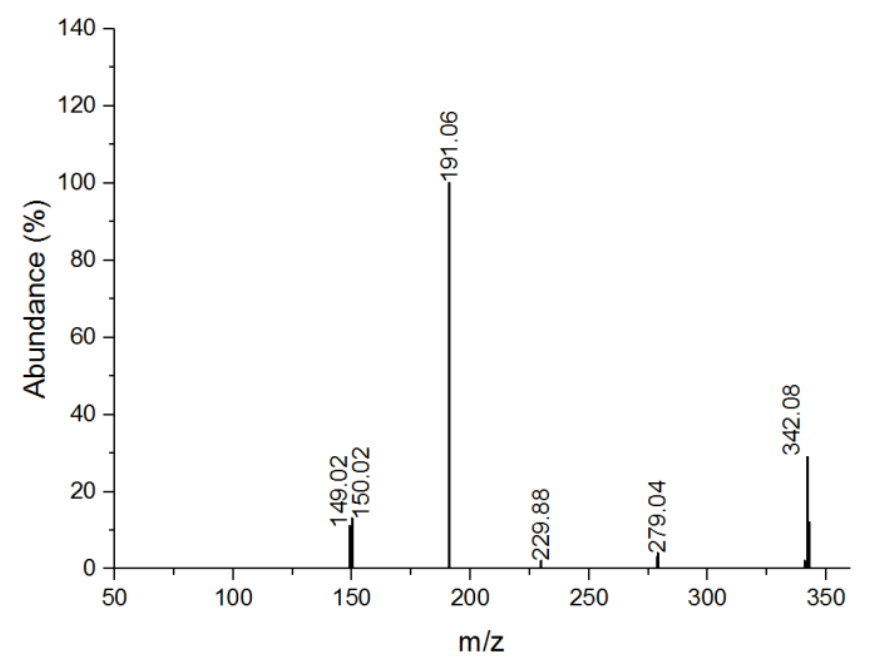

Figure S33. MS2 spectrum of TP 343 in negative ESI

TP 351: In positive ESI the MS2 spectrum of TP 351 is dominated by five mass peaks: the $[M+H]+$, $\mathrm{m} / \mathrm{z} 305.08$ (loss of -47 from $[\mathrm{M}+\mathrm{H}]+$ ), $\mathrm{m} / \mathrm{z} 287.07$ (loss of -18 from $\mathrm{m} / \mathrm{z} 305.08$ ), $\mathrm{m} / \mathrm{z} 193.07 \mathrm{and} \mathrm{m} / \mathrm{z}$ 191.05. The latter two fragments are characteristic for the triazole-piperazine unit. Next to the loss of -47 there is also a loss of -46 observable, giving rise to the fragment 306.09 . Thus it seems as if the structure contains a nitro group and at least a further oxygen-group due to the loss of -18 . 


\section{Supporting Information}

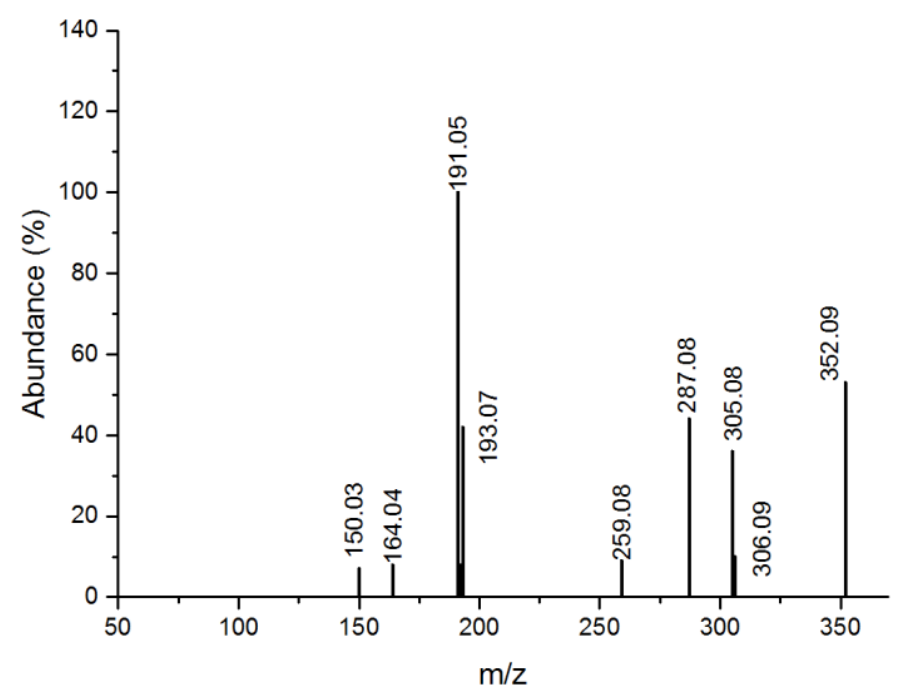

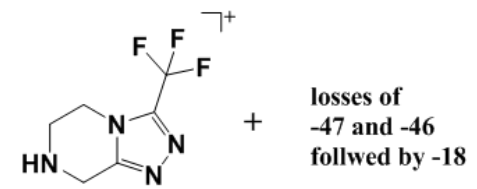

m/z 193.07

Figure S34. MS2 spectrum of TP 351 in positive ESI (left) and characteristic fragments ESI (right)

TP 445: The MS2 spectrum in positive ESI shows a loss of -18 from the $[M+H]+$ to $m / z 428.08$ followed by a loss of -47 to $\mathrm{m} / \mathrm{z} 381.08$ which speaks for the presence of a hydroxyl and a nitro group. The fragments $\mathrm{m} / \mathrm{z} 193.07$ and 191.05 can be assigned to the unchanged triazole-piperazine unit while characteristic fragment for the benzyol unit are not detected and thus, this part must been altered. Base peak of the MS2 spectrum in negative ESI is $\mathrm{m} / \mathrm{z} 353.09$. Second intense fragment is $\mathrm{m} / \mathrm{z} 191.06$ which, as seen in positive ESI, can be assigned to the unchanged triazole-piperazine unit.
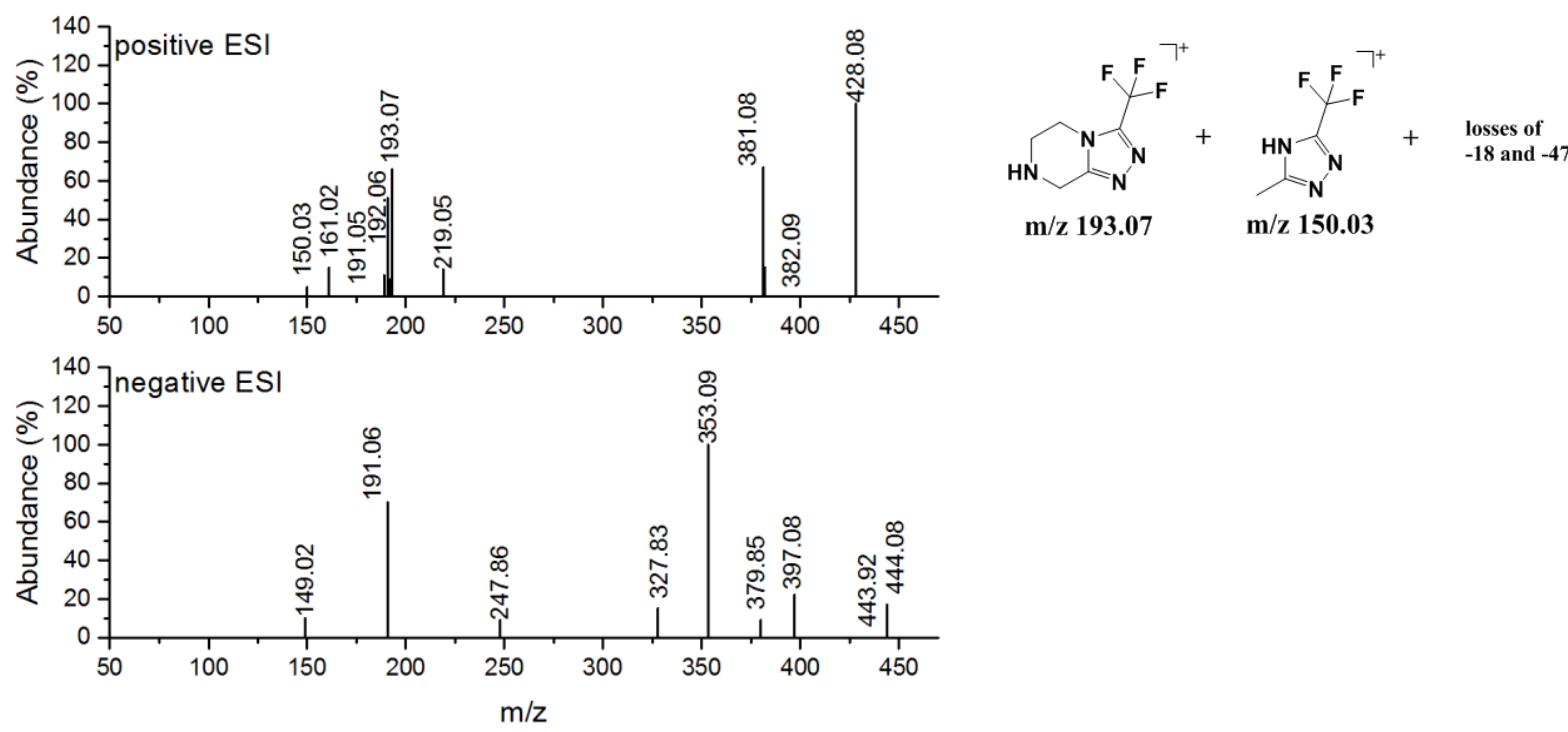

Figure S35. MS2 spectra of TP 445 in positive and negative ESI (left) and characteristic fragments ESI

(right)

TP 438: In positive ESI TP 438 shows a loss of -44 from $[M+H]+$ to its base peak, $m / z 395.09$ follwed by a loss of -18 to fragment $\mathrm{m} / \mathrm{z}$ 377.08. Assigning these losses to $\mathrm{CO} 2$ and $\mathrm{H} 2 \mathrm{O}$, at least three oxygen atoms are contained in the structure. Furthermore, characteristic fragments for the triazolepiperazine unit ( $\mathrm{m} / \mathrm{z}$ 193.07) and for the benzyol unit ( $\mathrm{m} / \mathrm{z} 145.03)$ can be observed. In negative ESI $\mathrm{m} / \mathrm{z} 393.08$ is the base peak, which corresponds with the MS2 of positive ESI. And also in negative ESI the characteristic fragment for the triazole-piperazine unit can be observed. Calculating the molecular formula from the exact mass gives $\mathrm{C} 16 \mathrm{H} 12 \mathrm{~F} 6 \mathrm{~N} 4 \mathrm{O} 4$ with a double bond equivalent of 10 as 


\section{Supporting Information}

possible result. Thus, the basic structure of STG might be conserved with additional three oxygen atoms and without the primary amine.
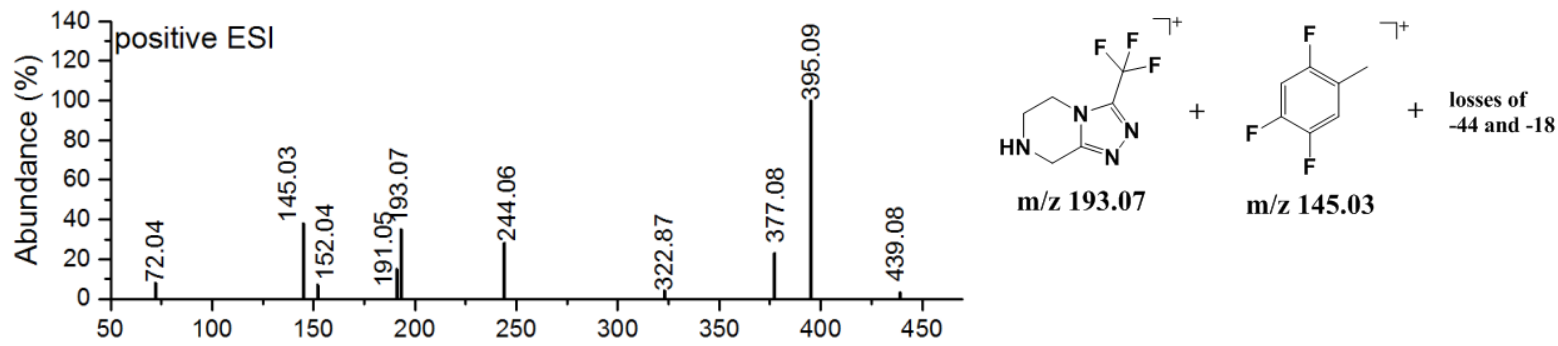

m/z 193.07

$\mathrm{m} / \mathrm{z} 145.03$

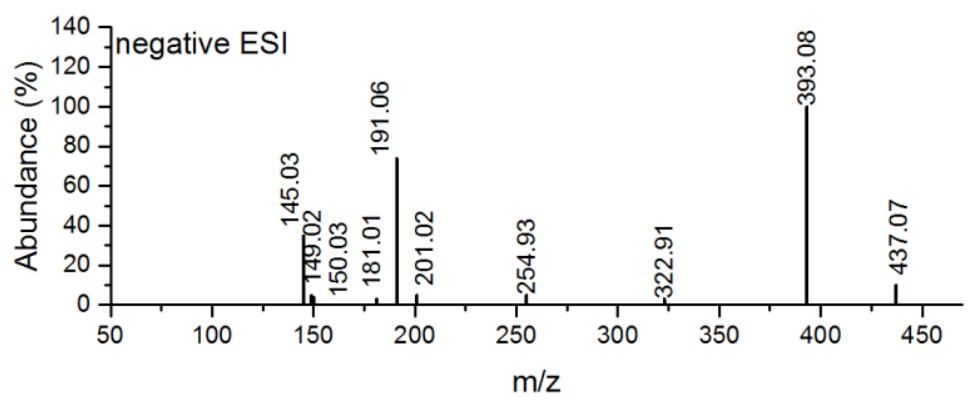

Figure S36. MS2 spectra of TP 438 in positive and negative ESI (left) and characteristic fragments in positive ESI (right)

TP 426: TP 426 shows a characteristic fragment for the benzyol unit $(\mathrm{m} / \mathrm{z} 145.03)$ but none for the triazole-piperazine unit. The fragments of the high mass region have only low intensity and thus, neutral losses cannot be assigned.
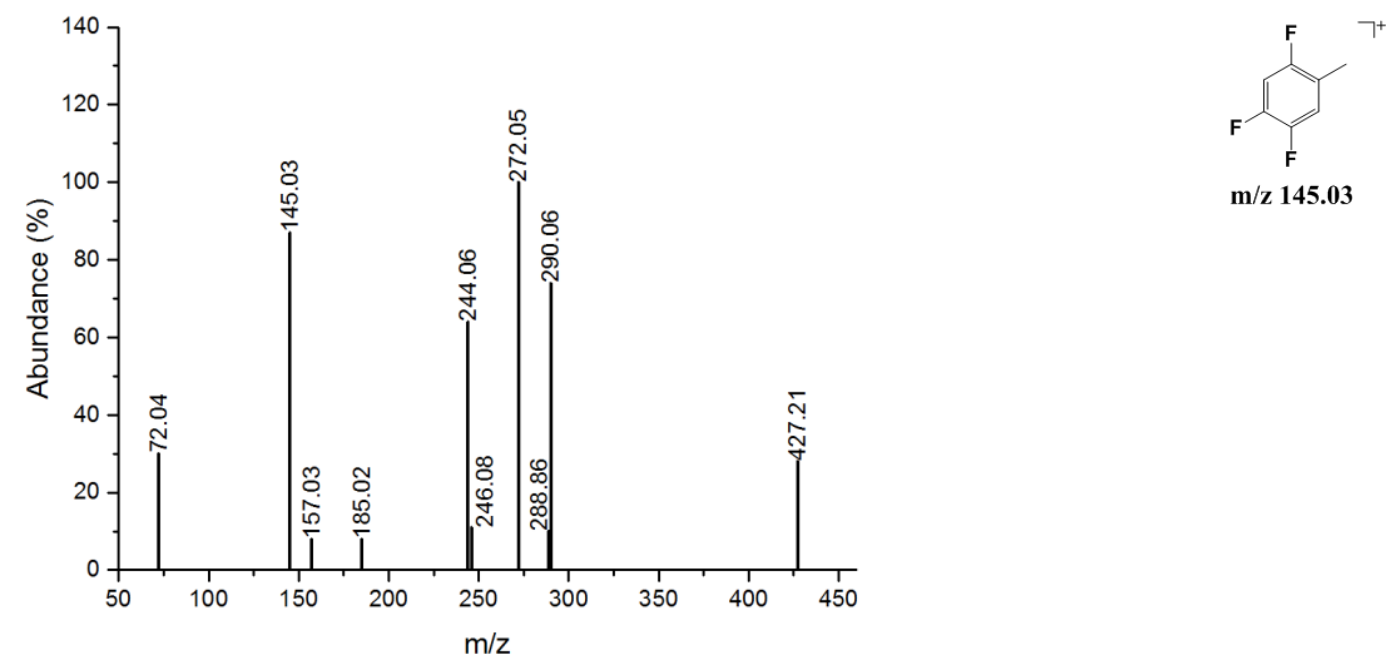

Figure S37. MS2 spectrum of TP 426 in positive ESI (left) and characteristic fragments ESI (right)

TP 425: TP 425 shows the characteristic fragments for the benzoyl unit ( $\mathrm{m} / \mathrm{z} 171.04,145.03,199.04)$ but at a very low intensity. Base peak is $\mathrm{m} / \mathrm{z} 242.08$. The quasi-molecular ion is observable at a very low intensity and there are no fragments in the high mass region which could be used for structure elucidation. 


\section{Supporting Information}

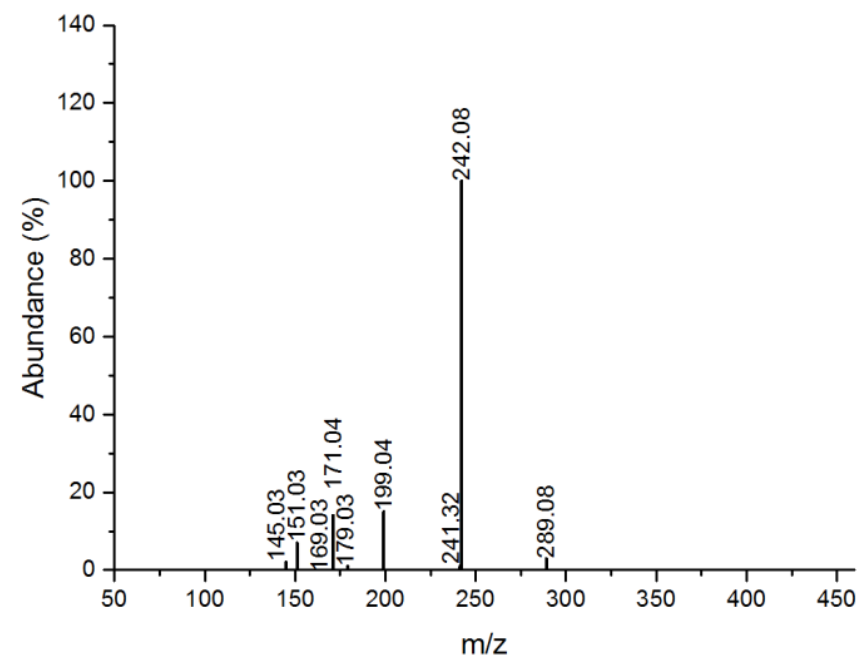

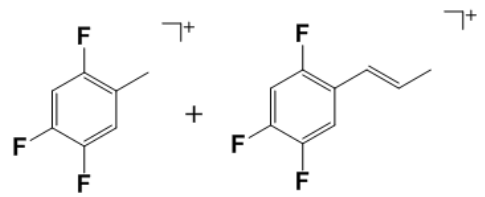

$\mathbf{m} / \mathbf{z} 145.03$

$\mathbf{m} / \mathbf{z} 171.04$

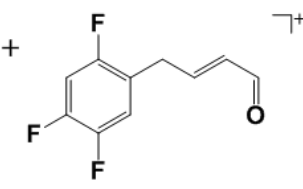

$\mathrm{m} / \mathrm{z} 199.04$

Figure S38. MS2 spectrum of TP 425 in positive ESI (left) and characteristic fragments ESI (right)

TP 463: In positive ESI no fragmentation occurred. In negative ESI no characteristic fragments could be observed, neither for the benzoyl nor for the triazole-piperazine unit. Fragment 424.08 is formed by a loss of -38 from the quasi-molecular ion, followed by a loss of -47 to give the base peak, $\mathrm{m} / \mathrm{z}$ 377.08. Second highest fragment is $\mathrm{m} / \mathrm{z} 136.01$ which is already known as intense fragment for other TPs but could not be assigned to any structure yet.
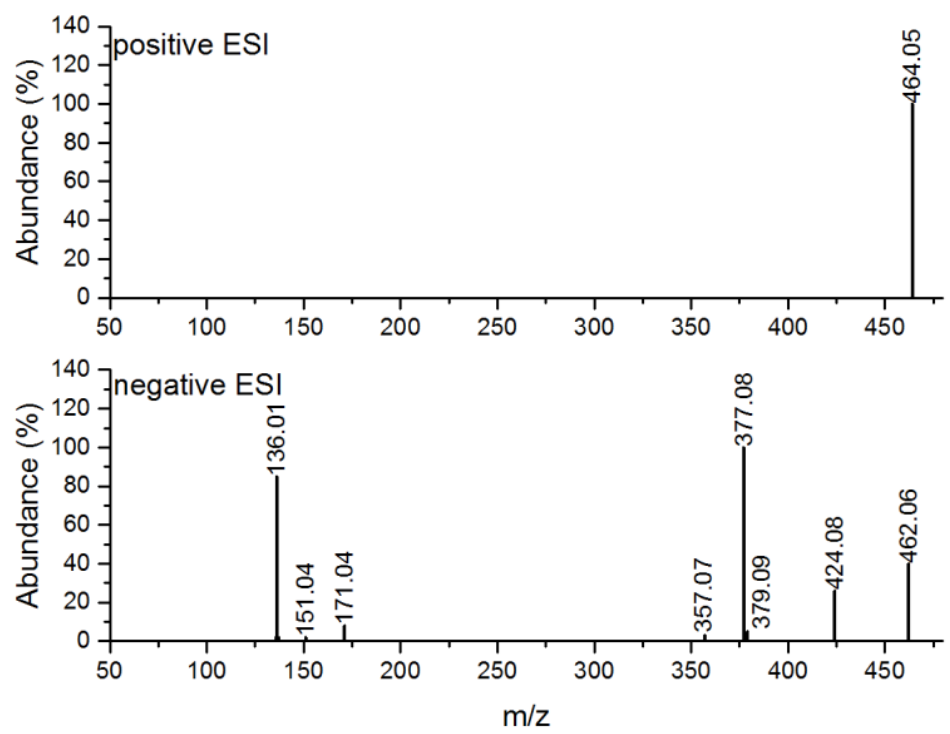

Figure S39. MS2 spectra of TP 425 in positive and negative ESI 


\section{Supporting Information}

Text S2: TFA is a known TP of STG ${ }^{4}$. Its formation is reported under radical reactions. The time series experiments under different $\mathrm{pH}$ values therefore were analysed for TFA formation under both reaction types, with t-BuOH and without.

With increasing $\mathrm{pH}$ formation of TFA increases when radicals were involved in the reaction. With the radical scavenger an initial TFA formation can be observed, maybe originating from a contamination.

TFA formation only accounts for a minor amount in the transformation of STG, with only $2 \%$ of the initial STG concentration. This result is in accordance with the study of Scheurer, et al. ${ }^{4}$.

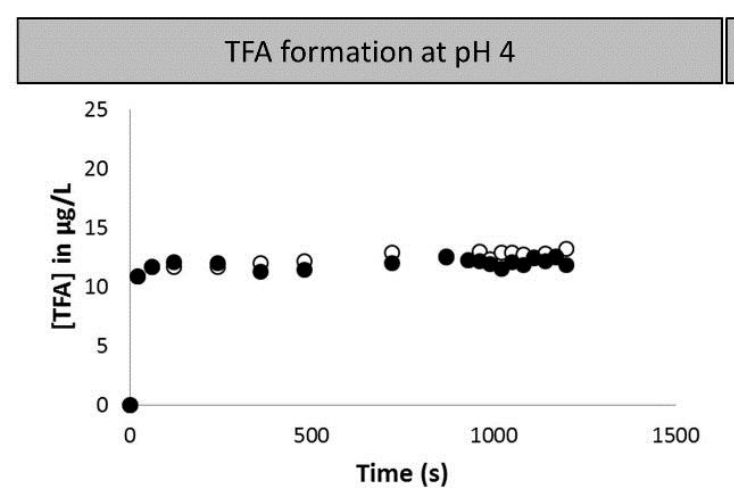

TFA formation at $\mathrm{pH} 6$
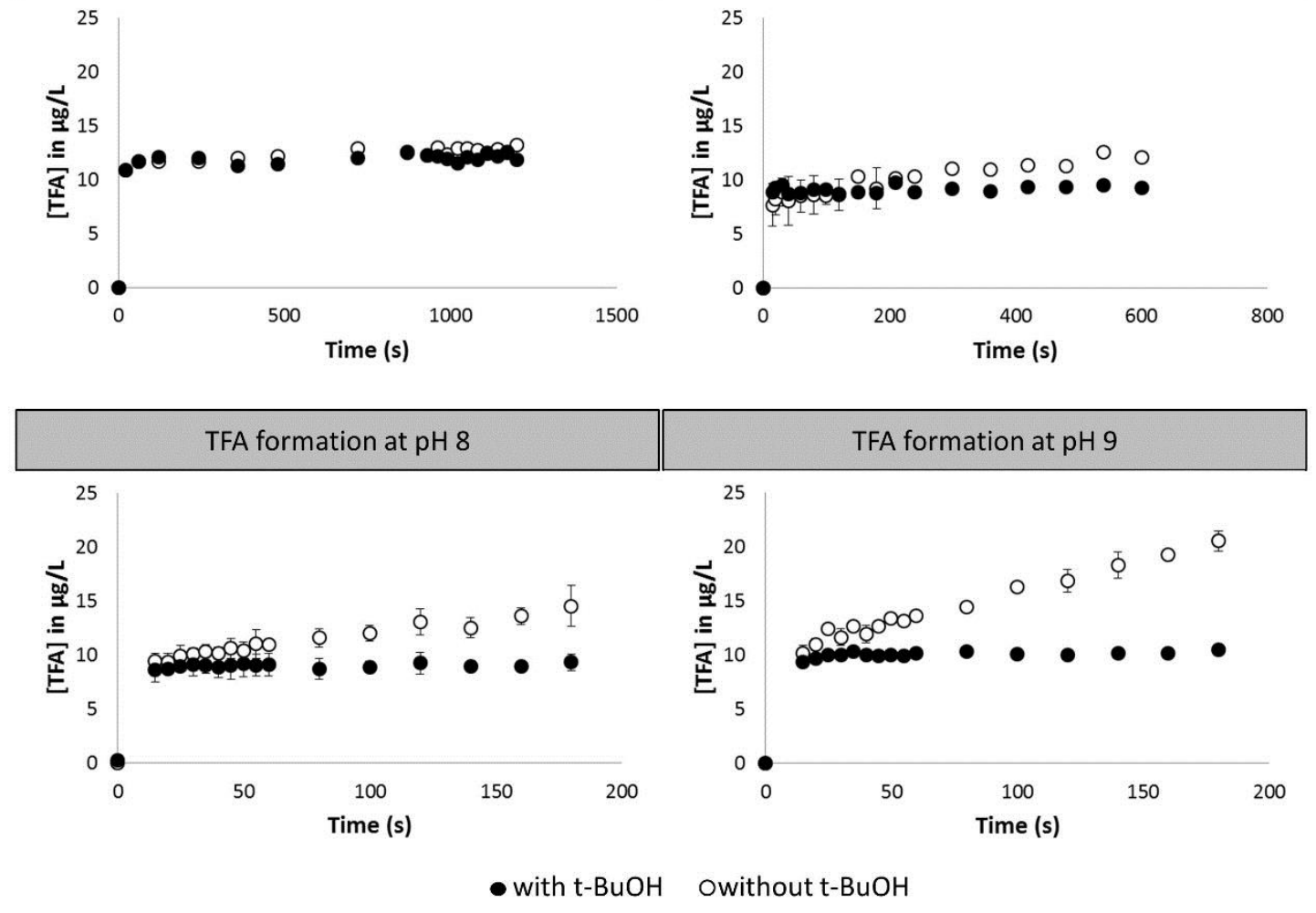

Figure S40: Formation of TFA in batch experiments ( $50 \mathrm{mM}$ phosphate buffer) at different pH values, with and without addition of $\mathrm{t}-\mathrm{BuOH}$ 


\section{Supporting Information}

Text S3: The kinetic experiments indicated a comparably low removal of STG in the ozonation. Labscale experiments in WWTP effluent (a) and ozonation in a pilot plant (b) at different ozone concentrations confirm this. In comparison to fexofenadine and candesartan STG showed slow and incomplete removal in both experimental set-ups while it showed faster attenuation than gabapentin and similar attenuation as denatonium.

Formation of TFA from STG was studied in lab-scale experiments in WWTP effluent at different ozone concentrations at non-spiked and spiked samples. Spike concentration of STG was $1 \mathrm{mg} / \mathrm{L}$. TFA concentrations increased with increasing ozone dosage; for spiked samples a maximum concentration of $75 \mu \mathrm{g} / \mathrm{L}$ was achieved, for non-spiked samples it was $70 \mu \mathrm{g} / \mathrm{L}$. The low difference between these values showed that the presence of STG has only minor influence on overall TFA formation. This is in accordance with findings of Scheurer, et al. ${ }^{4}$.

a) Attenuation in laboratory studies

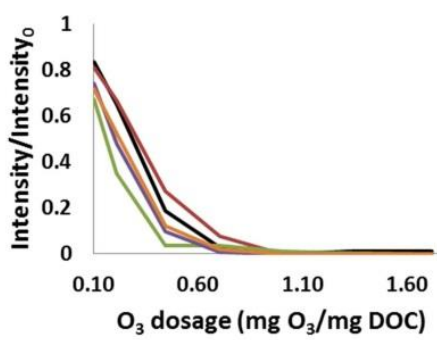

b) Attenuation in pilot plant

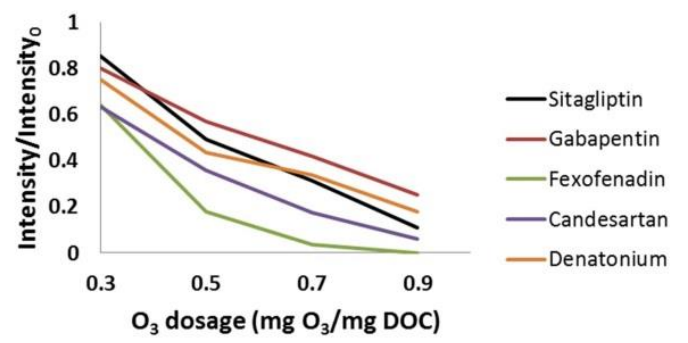

c) Formation of TFA in laboratory studies

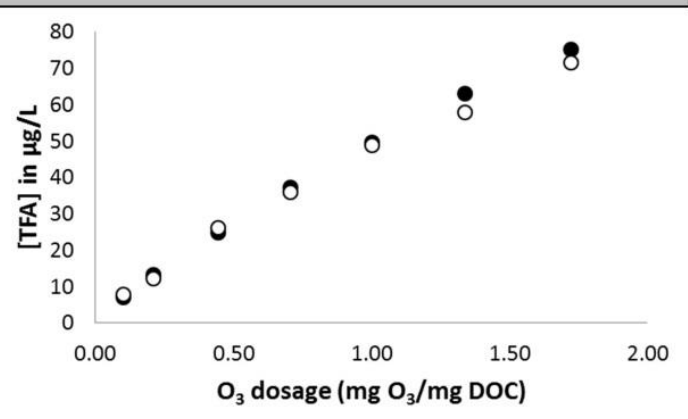

- STG spike O non-spiked

Figure S41: Comparison of STG attenuation with the attenuation of gabapentin, fexofenadine, candesartan and denatonium at different ozone dosages in (a) laboratory batch experiments in effluent from a German WWTP ( $D O C=12 \mathrm{mg} / \mathrm{L}, \mathrm{pH}=8, \mathrm{~T}=$ room temperature) and in (b) ozonation at a pilot plant in Sweden ( $\left.\mathrm{DOC}=10 \mathrm{mg} / \mathrm{L}, \mathrm{pH}=7, \mathrm{~T}=10-12^{\circ} \mathrm{C}\right)$. Formation of TFA (c) in laboratory batch experiments with spiked (spike concentration STG $=1 \mathrm{mg} / \mathrm{L}$ ) and non-spiked effluent from a German WWTP at different ozone dosages. 


\section{Supporting Information}

\section{Text S4: Biological degradability of TP 437 in MBBR treatment.}

Ozonation as treatment step in WWTPs usually is not applied as stand-alone technique but combined with subsequent treatment techniques. Oftentimes biological treatment is used for polishing.

Lab-scale batch experiments in an MBBR system were performed on an ozonated sample of STG. Ozonation was done in phosphate buffer including t-BuOH at pH 8 with an initial STG-concentration of $5 \mathrm{mg} / \mathrm{L}$. Ozone was added in an STG: $\mathrm{O}_{3}$-ration of 1:15 and the reaction was allowed to proceed for $2 \mathrm{~h}$. LC-ESI-QTOF analysis revealed the complete removal of STG, the main TP, TP 437, was formed to an high extend and traces of TP 406 also could be detected.

For lab-scale MBBR experiments, effluent from a pilot reactor at a German WWTP containing carriers were taken. Sample volume was set to $100 \mathrm{~mL}$, each sample bottle was equipped with 25 carriers (biomass per bottle: $1 \mathrm{~g} / \mathrm{L}$ ). Experiments were performed in triplicates for two different spike volumes (100 $\mu \mathrm{L}$ and $10 \mu \mathrm{L}$ from the ozonated sample). Sampling was performed at different time points over three days. In addition, samples from an ozonation pilot plant with subsequent MBBR treatment (HRT $=6 \mathrm{~h}$ ) were taken from a WWTP in Sweden and analysed for STG attenuation and TP 437 formation.

The lab-scale experiments showed only minor removal for both TPs over three days. STG, as background concentration, was evaluated as comparison and showed moderate removal. The labscale results for TP 437 were confirmed by the samples of the pilot plant, where TP 437 was formed during ozonation and could not be removed in the subsequent MBBR treatment. Here, STG showed a removal of about $50 \%$ during ozonation, however, during subsequent MBBR treatment no further attenuation could be achieved, possibly due to the very low HRT of only $6 \mathrm{~h}$. Further studies and labscale experiments would be needed to verify these results.

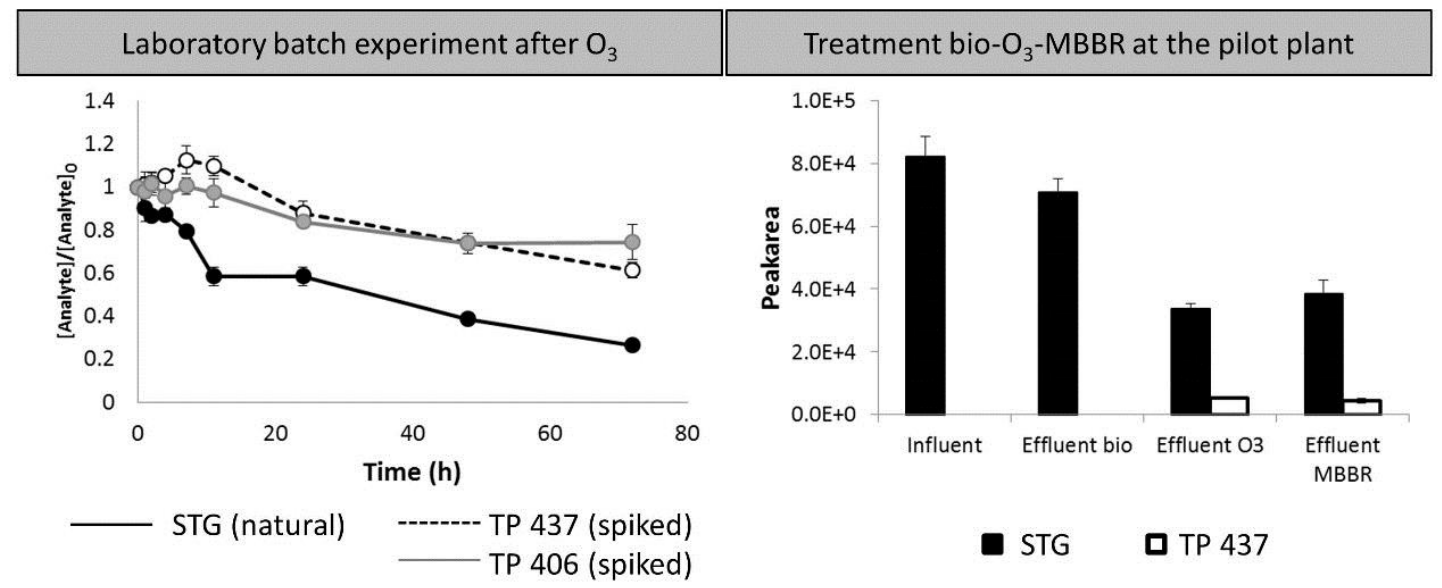

Figure S42: Attenuation of TP 437 and TP 406 in laboratory batch experiments spiked to effluent and carriers from a pilot reactor at a WWTP in Germany ( $D O C=12 \mathrm{mg} / \mathrm{L}, \mathrm{pH}=8, \mathrm{~T}=$ room temperature, STG was not spiked and is used as reference) and attenuation of STG and TP 437 during the whole treatment train of the pilot plant at a WWTP in Sweden (Influent and effluent bio taken from the municipal WWTP, effluent $\mathrm{O} 3$ and effluent MBBR from the pilot plant) 


\section{Supporting Information}

\section{References}

1. Yinon, J., Mass spectrometry of explosives: nitro compounds, nitrate esters, and nitramines. Mass Spectrom Rev 1982, 1, 257-307.

2. Chizov, O. S.; Kadentsev, V. I.; G., P. G.; Burstein, K. I.; Shevelev, S. A.; Feinsilberg, A. A., Chemical ionization of aliphatic nitro compounds. Organic Mass Spectrometry 1978, 13, (11), 611617.

3. McLafferty, F. W.; Turecek, F., Interpretation of mass spectra. University Science Books: Sausalito, California, 1993.

4. Scheurer, M.; Nodler, K.; Freeling, F.; Janda, J.; Happel, O.; Riegel, M.; Muller, U.; Storck, F. R.; Fleig, M.; Lange, F. T.; Brunsch, A.; Brauch, H. J., Small, mobile, persistent: Trifluoroacetate in the water cycle-Overlooked sources, pathways, and consequences for drinking water supply. Water Res 2017, 126, 460-471.

5. Lim, S.; McArdell, C. S.; von Gunten, U., Reactions of aliphatic amines with ozone: Kinetics and mechanisms. Water Research 2019, 157, 514-528. 